\title{
The CoreGram project: theoretical linguistics, theory development, and verification
}

\author{
Stefan Müller \\ German Grammar Group, \\ Institut für Deutsche und Niederländische Philologie, \\ Freie Universität Berlin
}

\begin{abstract}
This paper describes the CoreGram project, a multilingual grammar engineering project that develops HPSG grammars for several typologically diverse languages that share a common core. The paper provides a general motivation for doing theoretical linguistics the way it is done in the CoreGram project, and is therefore not exclusively targeted at computational linguists. I argue for a constraint-based approach to language rather than a generative-enumerative one and discuss issues of formalization. Recent advantages in language acquisition research are mentioned and conclusions on how theories should be constructed are drawn. The paper discusses some of the highlights in the implemented grammars, gives a brief overview of central theoretical concepts and their implementation in the TRALE system, and compares the CoreGram project with other multilingual grammar engineering projects.
\end{abstract} Keywords: Universal Grammar, Head-Driven Phrase Structure Grammar, multilingual grammar engineering, TRALE, HPSG, theoretical linguistics

The goal of the CoreGram project is to contribute to a better understanding of the constraints for specific human languages and of the constraints holding for human language in general or for certain language groups. To reach this goal we develop several large-scale computer-processable grammar fragments of several typologically diverse languages using a common core grammar. We believe that lin- 
guistic theories have reached a level of complexity that makes it necessary to implement grammars in order to verify their consistence (Section 1.2).

The theoretical framework we use is Head-Driven Phrase Structure Grammar (HPSG, Pollard and Sag 1994; Sag 1997) in the version that is described in detail in Müller 2013b. We are currently working on the following languages:

- German (Müller 2007b, 2009b, 2012; Müller and Ørsnes 2011, 2013a; Müller 2014a, 2015a)

- Danish (Ørsnes 2009; Müller 2009b, 2012; Müller and Ørsnes 2011, 2013a,b, 2015)

- Persian (Müller 2010b; Müller and Ghayoomi 2010; Müller et al. In Preparation)

- Maltese (Müller 2009a)

- Mandarin Chinese (Lipenkova 2009; Müller and Lipenkova 2009, 2013, In Preparation)

- Yiddish (Müller and Ørsnes 2011)

- English (Müller 2009b, 2012; Müller and Ørsnes 2013a)

- Hindi

- Spanish

- French

These languages belong to diverse language families (Indo-European, Afro-Asiatic, Sino-Tibetian), and among the Indo-European languages, the languages belong to different groups (Germanic, Romance, IndoIranian). Figure 1 provides an overview.

For implementation we use the TRALE system (Meurers et al. 2002; Penn 2004), which allows for a rather direct encoding of HPSG analyses (Melnik 2007). The grammars of German, Danish, Persian,

Figure 1:

Language families and groups of the languages covered in the CoreGram project

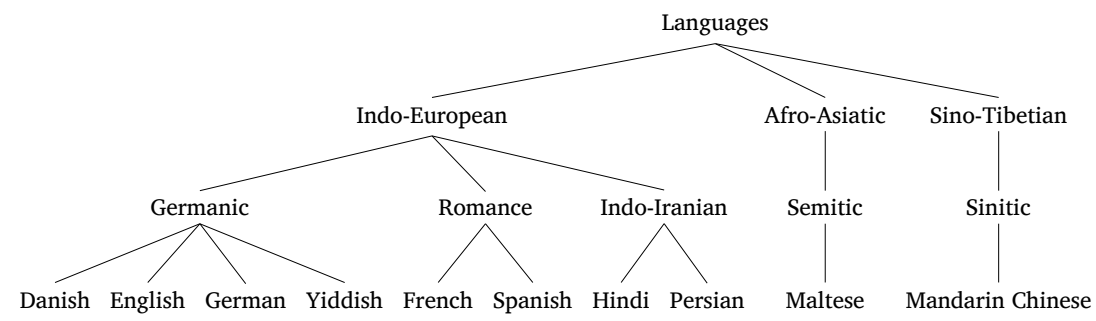


Maltese, and Mandarin Chinese are of non-trivial size and can be downloaded at http://hpsg.fu-berlin.de/Projects/CoreGram. html. They are also part of the next version of the Grammix virtual machine (Müller 2007a). The grammars of Yiddish and English are toy grammars that are used to verify cross-linguistic analyses of special phenomena. The grammar of Hindi is also a small fragment. I developed it together with Shravan Vasishth during a seminar at the University of Potsdam in 2006. The work on Spanish and French is part of ongoing work in the Sonderforschungsbereich 632, which started in 2012. See (Bildhauer 2008) for an implemented grammar of Spanish that will be converted into the format of the grammars mentioned above. As of February 2015, the grammars and test suites have the sizes shown in Table 1.

As is explained in Section 5.2, the grammars share some code. 14,523 lines are shared by at least two grammars. The lexical entries are those lexical items that are specified by the grammar writer, the lexical items are the lexical entries plus those lexical items that are licensed by lexical rules. As the table shows, there is a huge difference between languages with a rich inflection and clitics on the one hand, and languages without inflection, such as Mandarin Chinese, on the other hand. The test suite for the German grammar is the largest; however, many phenomena that work for German are also implemented for other languages but are not part of the respective test suites yet. An example for this is coordination. For Persian we have three test suites: The first consists of the one hundred sentences used by Bahrani

\begin{tabular}{lrrrl}
\hline & lines & $\begin{array}{r}\text { lexical } \\
\text { entries }\end{array}$ & $\begin{array}{r}\text { lexical } \\
\text { items }\end{array}$ & $\begin{array}{l}\text { test } \\
\text { items }\end{array}$ \\
\hline German & 18,060 & 300 & 11,150 & 361 \\
Danish & 16,373 & 120 & 1,325 & 231 \\
Persian & 17,640 & 1,981 & 65,847 & $100+216+130$ \\
Maltese & 10,046 & 95 & 2,362 & 134 \\
Mandarin Chinese & 10,718 & 564 & 855 & 104 \\
Yiddish & 10,383 & 26 & 60 & 34 \\
English & 9,955 & 49 & 97 & 23 \\
French & 11,831 & 43 & 61 & 20 \\
Hindi & 8,907 & 32 & 90 & 46 \\
\hline
\end{tabular}

Table 1:

Sizes of grammars and test suits included in CoreGram 
et al. (2011, p. 405-406) in their GPSG project. 216 sentences comprise our main test suite, which mainly contains examples from the literature, constructed examples, and ungrammatical strings that were discovered during grammar development. The third test suite contains 130 randomly selected sentences from the Peykare corpus (Bijankhan 2004), a balanced corpus provided by the University of Tehran and the Higher Council for Informatics of Iran.

We believe that working out large-scale computer-implemented grammars is the best way to verify the consistency of linguistic theories. Much linguistic work is published in journal articles, but the underlying assumptions of each article may be different, so that it is difficult to imagine a coherent view that incorporates all insights. Even for articles written by the same author there is no guarantee that basic assumptions are shared between articles, since it can take several years for individual papers to be published. Hence, I believe that books are the best format for describing linguistic theories, and ideally, such theories should be backed up by computer implementations. The larger fragments of the CoreGram project will be documented in a series of book publications. The first book in this series was (Müller 2007b), which describes a fragment of German that is implemented in the grammar BerliGram. Three further books are in preparation and will be submitted to the series Implemented Grammars by Language Science Press: one on the Persian Grammar developed in the PerGram project (Müller et al. In Preparation), one on the Danish Grammar developed in the DanGram project (Müller and Ørsnes 2015), and one on the Mandarin Chinese grammar developed in the ChinGram project (Müller and Lipenkova In Preparation).

The remainder of this paper is structured as follows: the rest of this section describes desiderata for linguistic theories and discusses the importance of formalization, with special focus on mainstream theories and research programs such as GB, Minimalism, and Construction Grammar. Section 2 discusses the way in which theories of our linguistic knowledge should be constructed. It compares Minimalist approaches with the more data-driven approach taken in the CoreGram project. Many Minimalist approaches start with certain assumptions and then try to show that it is possible to account for all languages with these fundamental assumptions. Recent evidence from language acquisition shows that this is not a viable research strategy and that 
grammars should be motivated on a language-specific basis. The generative research tradition was criticized by typologists like Haspelmath (2010a), Dryer (1997), and Croft (2001, Section 1.4.2-1.4.3), claiming that the generative methodology was fundamentally flawed and that descriptive categories should be language-specific. I will show why the CoreGram project does not run into methodological problems and suggest a middle way between mainstream generative grammar and radical views like the one held by Croft. Following the discussion of theory construction in Section 2, Section 3 shows some highlights from the various CoreGram grammars. Section 4 discusses basic theoretical assumptions for the treatment of valence, constituent order, morphology, semantics, and information structure, and Section 5 provides details on how things are implemented in the TRALE system. Section 6 compares the CoreGram project with other multilingual projects like ParGram and DELPH-IN. Finally, Section 7 deals with evaluation, grammar profiling and testing, and Section 8 draws some conclusions.

\section{1}

Desiderata for linguistic theories

This section discusses desiderata for linguistic theories and shows that the framework that is assumed in the CoreGram project, namely HPSG, fulfils all of them.

\subsubsection{Non-transformational, constraint-based approach}

While psycholinguistic experiments at first seemed to confirm the Derivational Theory of Complexity (Miller and McKean 1964; Savin and Perchonock 1965; Clifton and Odom 1966), so that Chomsky assumed it to be correct until 1968 (Chomsky 1976, p. 249-250), it was later shown that the initial experiments were flawed and that transformations are not psycholinguistically real (Fodor et al. 1974, p. 324). Since then it has become customary to say that transformations are metaphors (for instance in Chomsky 2001, Footnote 4). This, of course, begs the question why one should formulate one's theories in metaphors (see also Jackendoff 2011, p. 599). This question is even more pressing since a lot of Minimalist theorizing is now done under the label of Biolinguistics and the assumed processes are claimed to be psycholinguistically real. For instance, Chomsky (2001, p. 11, 12, 15; 2007 , p. 3,$12 ; 2008$, p. $138,145,146,155)$ refers to aspects of pro- 
cessing and memory requirements (see also Marantz 2005, p. 440, and Richards 2015). However, structure building processes that start with the combination of words and assume later reorderings are highly implausible from a psycholinguistic point of view. As was pointed out by Labelle (2007), human short-term memory is simply too limited to be able to compute complex structure in the way it is envisaged by current Minimalist theories. Models that crucially rely on the order of application of combinatorial operations fail, since we neither use our linguistic knowledge exclusively bottom-up nor exclusively top-down. Phillips (2003) suggested a theoretical variant that allows for incremental parsing, but first, this is tailored towards parsing and ignores generation, and second, it is incompatible with much of the rest of the Minimalist theories.

The way out of all of these problems is a clear separation between competence and performance and a declarative, constraintbased statement of linguistic constraints that do not make any claims about the order of constraint application (Sag and Wasow 2011; Jackendoff 2011, p. 600). The order of application is constrained by performance models, which are an important part of a theory about language and have to be combined with competence models. Proponents of usage-based approaches often reject the competence-performance distinction, but as soon as a grammar contains grammar rules or schemata that can be applied recursively, one has to explain why sentences have a maximal length, why we cannot do center-embeddings with more than four levels and so on. An example of such a schema would be a schema that licences relative clauses. Since relative clauses may contain NPs, and NPs may in turn contain relative clauses, we have a recursive grammar that licences infinitely many sentences. (Bannard et al. 2009, proponents of Construction Grammar, use a context-free grammar, a kind of grammar that clearly allows for recursive structures). The limitations with respect to sentence length and embedding are due to factors such as our short term memory and have to be explained by a performance model that takes these factors into account (Gibson 1998).

HPSG is a constraint-based theory which does not make any claims about the order of application of combinatorial processes. Theories in this framework are just statements about relations between linguistic objects or between properties of linguistic objects 
and, hence, compatible with psycholinguistic findings and processing models (Sag and Wasow 2011).

Pullum and Scholz (2001) and Pullum (2007) discuss further advantages of model-theoretic, and hence constraint-based, proposals: they allow the construction of partial structures, can deal with graded grammaticality, and no claims about the infinitude of language are necessary.

As Pullum and Scholz note we can assign the structure in Figure 2 to the fragment and of the in a sentence like (1):

(1) That cat is afraid of the dog and of the parrot.

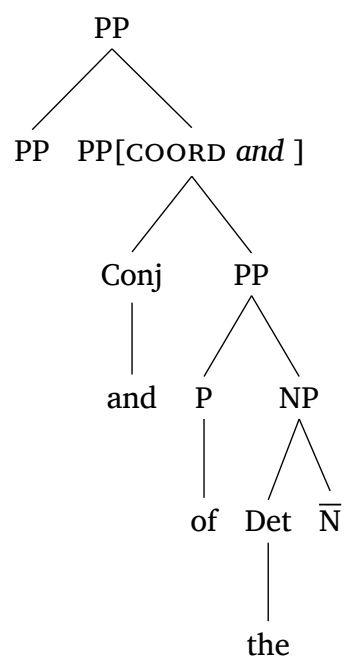

Figure 2:

Structure of the fragment "and of the" following Pullum and Scholz (2001, p. 32)

If we hear the we know that an $\overline{\mathrm{N}}$ will follow, if we hear of, we will know that of will head a PP. and usually is part of symmetric coordinations, so we know that the first part of the coordination will be a PP too. So, the information from lexical items and dominance schemata licenses a complex structure in constraint-based models, while nothing is generated in generative-enumerative models. and of the is just not a member of a set of well-formed expressions.

This property of constraint-based approaches also comes in handy when we want to explain the robustness of human sentence processing. In the case of unknown words, information from syntax and semantics can be used to draw inferences about the material that is missing. For instance in an utterance like (2), in which information about 
$\mathrm{XXX}$ is missing, the hearer can infer that XXX must be a verb and that it must have three arguments. (This argument is also due to Pullum and Scholz 2001, Section 3.3, who make it in a slightly different form.)

(2) Could you XXX me the salt, please?

Hence, the hearer arrives at a prototypical ditransitive verb, a verb of change of possession, that is, something like give or pass. In current Minimalist models nothing would happen since structure building and movement is triggered by lexical items and their features, but if they are absent or unknown, the derivation does not start. ${ }^{1}$

While constraint-based approaches can explain markedness of structures by the number and strength of constraints that are violated by a given example, this is not possible in generative-enumerative approaches. For a discussion of an attempt to incorporate markedness into the picture of generative-enumerative models, see (Chomsky 1975, Chapter 5; Chomsky 1964). For a rejection of these proposals see (Pullum and Scholz 2001, p. 29).

Finally, constraint-based models do not have to make any claims about the infinitude of language. While it is usually claimed that language is infinite by proponents of generative-enumerative proposals,

${ }^{1}$ Chomsky (2007, p. 6) writes: A Merge-based system of derivation involves parallel operations. Thus if $X$ and $Y$ are merged, each has to be available, possibly constructed by (sometimes) iterated Merge. The process has a loose resemblance to early theories of generalized transformations, abandoned in the early 1960s for good reasons, now resurrected in a far simpler form for better reasons. But a generative system involves no temporal dimension. In this respect, generation of expressions is similar to other recursive processes such as construction of formal proofs. Intuitively, the proof "begins" with axioms and each line is added to earlier lines by rules of inference or additional axioms. But this implies no temporal ordering. It is simply a description of the structural properties of the geometrical object "proof." The actual construction of a proof may well begin with its last line, involve independently generated lemmas, etc. The choice of axioms might come last. The same is true of generation vs production of an expression, a familiar competence-performance distinction. This seems to indicate a constraint-based position. However, even if a constraint-based view is assumed in principle, there are lots of unsolved problems with specific Minimalist proposals. For instance, some approaches assume the existence of unvalued features that acquire a value during a derivation. What happens if the information about these features is not available to the hearer? According to Minimalist theorizing, the derivation should crash. But as (2) just shows, it does not crash but results in partial, underspecified information. 
no such claims are necessary in the model-theoretic world. Those who claim that language is infinite and biologically real are faced with the paradox that infinitely many members of the infinite set are not biologically real, that is, they can never be realized because of our limited resources (Postal 2009). Model-theoretic approaches do not have to assume infinite sets only to throw away most of them because of performance considerations; rather, they pair the performance model with the competence model directly and therefore end up with theories that are psycholinguistically and biologically plausible.

As I showed in (Müller 2010a, Chapter 3.6.4; 2013c), the combinatory operations of Minimalism as defined in (Chomsky 2008) and (Stabler 2001) correspond to three of the schemata used in HPSG grammars since at least (Pollard and Sag 1994): Merge corresponds to the Head-Specifier Schema and the Head-Complement Schema of HPSG, and Move corresponds to the Head-Filler Schema. So, ideology and rhetorics aside, what we have here is a constraint-based, declarative formalization of Minimalist proposals. Of course, a lot of questions have to be asked about current Minimalist analyses; some of them will be addressed in Section 2 .

\subsubsection{Sign-based, parallel architecture}

As was shown by Marslen-Wilson (1975) in the 1970s and confirmed later by many studies, we process linguistic and non-linguistic information as soon as it is available to us, and there is no ordering of strictly encapsulated modules of processing. Tanenhaus et al. (1995, 1996) used eye-tracking techniques to establish that we know the referents of NPs even if we just heard a determiner and an adjective. The authors showed that stress on the adjective is interpreted immediately as a sign of contrast, leading to right inferences being drawn and the only possible object in a specific scene being looked at. The studies demonstrated that constraints from phonology, syntax, and information structure are evaluated immediately and that information is processed as soon as it is available. We can use it and draw inferences even though we may not be able to assign a full syntactic structure to a certain phrase yet. Such findings are compatible with architectures that assume that all linguistic levels are accessible simultaneously such as HPSG, LFG, Construction Grammar and Jackendoff's Parallel Architecture (Jackendoff 1999, 2011; Kuhn 2007). 


\section{Stefan Müller}

1.1 .3

Possibility to include

non-headed and phrasal constructions

I agree with Jackendoff (2008, 2011), Jacobs (2008), Sag (2010), and others that one needs more than some very general binary-branching schemata to deal with language in its full richness in non-stipulative ways. For instance, Jackendoff (2011) pointed out that none of the elements in N-P-N constructions like (3) can be identified as the head. Instead of the usual head-argument structures ( $\overline{\mathrm{X}}$ or equivalent), Jackendoff (2008) suggests that the N, P, and N are combined into an NP or advP and that the structure as such is unheaded.

(3) student after student

[NP/advP N-P-N]

The sentences in (4), which were mentioned by Jackendoff and Pinker (2005, p. 220) and whose German equivalent was discussed in detail by Jacobs (2008), are further examples of a construction that is best handled as a headless construction. ${ }^{2}$

(4) a. Off with his head!

b. Into the trunk with you!

Hence, I believe that additional schemata or phrasal constructions in the sense of Construction Grammar or Simpler Syntax (Culicover and Jackendoff 2005) are needed. It is an empirical issue to what extent phrasal constructions are needed and where Merge-like combinations together with a rich lexicon are sufficient or rather necessary, and the CoreGram project contributes to this discussion. See, for instance, (Müller and Lipenkova 2009) for a phrasal treatment of serial verbs in Mandarin Chinese, and (Ørsnes 2009) for a phrasal treatment of preposed negation in Danish.

\subsubsection{Core-periphery distinction}

Given that the name of the project is CoreGram, some words on the core-periphery distinction are in order.

Chomsky (1981, p. 7-8) suggests dividing languages into a core part and a periphery. All regular parts belong to the core. The core

\footnotetext{
${ }^{2}$ See (Müller 2011) for an account of Jacobs' data using an empty verbal head and an abstract antipassive morpheme, and (Müller 2015b, Section 12.11.9.1) for discussion.
} 
grammar of a language is assumed to be an instance of Universal Grammar (UG), the genetically determined innate language faculty of human beings. Idioms and other irregular parts of a language belong to the periphery. Critics of Chomsky's Principle and Parameters approach have pointed out that a rather large proportion of our languages consist of, or interact with, irregular constructions, and that the borders between core and periphery cannot be drawn easily and are often motivated theory-internally only (Jackendoff 1997, Chapter 7; Culicover 1999; Ginzburg and Sag 2000, p. 5; Newmeyer 2005, p. 48; Kuhn 2007, p. 619). For instance, Nunberg et al. (1994) pointed out that many English idioms interact with syntax. See also (Müller 2010a, p. 350) for interactions of idioms with verb placement, V2, and passive in German.

So, I do not think that it is justified to ignore phenomena that are claimed to belong to the periphery. Rather, I agree with Bender and Flickinger (1999) and Bender (2008, p. 20-21) that studying phenomena that are traditionally assigned to the periphery may discriminate between possible analyses of the alleged core phenomena.

It should be noted however that the methodology described in Section 2.2 results in a separation of core and periphery: Core constraints in the sense of the CoreGram project are those constraints that are shared by at least two languages. All other constraints are specific for a single language and constitute the periphery of the respective languages. This notion of periphery is very different from the Chomskian one: Depending on the version of the theory we look at, the periphery in the Chomskian sense includes phenomena like Exceptional Case Marking (Chomsky 1981, p.70), which are common in a lot of languages and are, hence, assigned to the core in our setting. Another example is Jackendoff's student after student construction, which can be found in several languages (König and Moyse-Faurie 2009) and which we would count to the core grammar, but which would probably not be seen as part of the core grammar in the Chomskyan sense. Please refer to Section 2.2 for details of the organization of CoreGram and to (Müller 2014c) for a general discussion of the core-periphery distinction. 
The work of Noam Chomsky pioneered the formalization of linguistic theories. In his early writings he states that formalization is necessary for progress in linguistics:

Precisely constructed models for linguistic structure can play an important role, both negative and positive, in the process of discovery itself. By pushing a precise but inadequate formulation to an unacceptable conclusion, we can often expose the exact source of this inadequacy and, consequently, gain a deeper understanding of the linguistic data. More positively, a formalized theory may automatically provide solutions for many problems other than those for which it was explicitly designed. Obscure and intuition-bound notions can neither lead to absurd conclusions nor provide new and correct ones, and hence they fail to be useful in two important respects. I think that some of those linguists who have questioned the value of precise and technical development of linguistic theory have failed to recognize the productive potential in the method of rigorously stating a proposed theory and applying it strictly to linguistic material with no attempt to avoid unacceptable conclusions by ad hoc adjustments or loose formulation. (Chomsky 1957, p. 5)

In a book that appeared some years later, Manfred Bierwisch argued for machine processable implementations of theoretical analyses:

It is therefore very possible that the rules that we have formulated generate sentences which are outside of the set of grammatical sentences in an unpredicted way; that is, they violate grammaticality due to properties that we did not deliberately exclude from our analysis. This is what is meant by the statement that a grammar is a hypothesis about the structure of a language. A systematic examination of the implications of a grammar that is appropriate for natural languages surely is a task that cannot be solved manually anymore. This task could be approached by implementing the grammar as a calculation task on a computer, so that it can be verified 
to which degree the result deviates from the language to be described. (translated from Bierwisch 1963, p. $163^{3}$ )

I wholeheartedly agree with Bierwisch's statement, given that after the time of his writing enormous headway has been made both empirically and theoretically. For instance, Ross (1967) discovered constraints on reordering constituents and non-local dependencies; Perlmutter (1978) discovered unaccusative verbs in the 1970s; and theories were developed for dealing with case (Yip et al. 1987; Meurers 1999c; Przepiórkowski 1999), verbal complex formation, and partial fronting (Evers 1975; Grewendorf 1988; Hinrichs and Nakazawa 1994; Kiss 1995; G. Müller 1998; Meurers 1999b; Müller 1999, 2002; De Kuthy 2002). All these phenomena, and a lot more, interact!

To emphasize this point, I give another quotation from Steve Abney, who worked within the GB framework:

A goal of earlier linguistic work, and one that is still a central goal of the linguistic work that goes on in computational linguistics, is to develop grammars that assign a reasonable syntactic structure to every sentence of English, or as nearly every sentence as possible. This is not a goal that is currently much in fashion in theoretical linguistics. Especially in Government-Binding theory (GB), the development of large fragments has long since been abandoned in favor of the pursuit of deep principles of grammar. The scope of the problem of identifying the correct parse cannot be appreciated by examining behavior on small fragments, however deeply analyzed. Large fragments are not just small fragments several times over-there is a qualitative change when one be-

\footnotetext{
${ }^{3}$ Original from (Bierwisch 1963, p. 163): Es ist also sehr wohl möglich, daß mit den formulierten Regeln Sätze erzeugt werden können, die auch in einer nicht vorausgesehenen Weise aus der Menge der grammatisch richtigen Sätze herausfallen, die also durch Eigenschaften gegen die Grammatikalität verstoßen, die wir nicht wissentlich aus der Untersuchung ausgeschlossen haben. Das ist der Sinn der Feststellung, daß eine Grammatik eine Hypothese über die Struktur einer Sprache ist. Eine systematische Überprüfung der Implikationen einer für natürliche Sprachen angemessenen Grammatik ist sicherlich eine mit Hand nicht mehr zu bewältigende Aufgabe. Sie könnte vorgenommen werden, indem die Grammatik als Rechenprogramm in einem Elektronenrechner realisiert wird, so daß überprüft werden kann, in welchem Maße das Resultat von der zu beschreibenden Sprache abweicht.
} 
gins studying large fragments. As the range of constructions that the grammar accommodates increases, the number of undesired parses for sentences increases dramatically. (Abney 1996, p. 20)

In addition, it is a goal of much current linguistic theorizing to formulate constraints that hold for all languages or at least for certain classes of languages. As a consequence, it is not sufficient to study the interaction between phenomena solely on the basis of one language: Changing the constraints for a certain phenomenon in one language may be compatible with all phenomena that are relevant for the language under discussion, but it may well be the case that unexpected interactions with other phenomena in another language emerge. Verifying the consequences of a simple change of a principle therefore results in a complexity that cannot be handled by human beings. It is therefore necessary to formalize the theories in a way that makes them implementable as computer-processable grammars. After checking the grammar for consistency, a computer grammar can be used to analyze systematically constructed test suites containing thousands of grammatical sentences and ungrammatical word sequences or large corpora containing naturally occurring data. Such parses can be used to verify that the grammar makes the right predictions as far as the empirical facts are concerned (Müller 1999, Chapter 22; Oepen and Flickinger 1998; Bender 2008, Müller 2013a, Section 3.7.2; Müller 2015b, Section 3.7.2). In addition, generators can be used to produce utterances that correspond to a certain meaning. If ill-formed strings are generated, this is an indicator for missing constraints in the grammar.

After more than 55 years of work in transformational grammar, one has to note that there are no large-scale implemented fragments on the basis of transformational analyses. Chomsky made important contributions to the theory of formal languages that are still relevant in computer science (Chomsky 1959), but in 1981 he turned his back on precisely worked-out solutions:

I think that we are, in fact, beginning to approach a grasp of certain basic principles of grammar at what may be the appropriate level of abstraction. At the same time, it is necessary to investigate them and determine their empirical adequacy by developing quite specific mechanisms. We should, 
then, try to distinguish as clearly as we can between discussion that bears on leading ideas and discussion that bears on the choice of specific realizations of them. (Chomsky 1981, p. 2-3)

He made it explicit in a letter to Natural Language and Linguistic Theory:

Even in mathematics, the concept of formalization in our sense was not developed until a century ago, when it became important for advancing research and understanding. I know of no reason to suppose that linguistics is so much more advanced than 19th century mathematics or contemporary molecular biology that pursuit of Pullum's injunction would be helpful, but if that can be shown, fine. For the present, there is lively interchange and exciting progress without any sign, to my knowledge, of problems related to the level of formality of ongoing work. (Chomsky 1990, p. 146)

The consequence of this change is a very large number of publications in Mainstream Generative Grammar, many of which make incompatible assumptions, so that it is not clear how insights from different publications can be combined. A case in point are the many different definitions of the rather central concept of government (see Aoun and Sportiche 1983 for an overview).

This was repeatedly criticized in the 1980 s, for instance by the practitioners of GPSG (Gazdar et al. 1985, p. 6; Pullum 1985, 1989; Pullum 1991, p. 48; Kornai and Pullum 1990). The lack in precision, missing details, ${ }^{4}$ and frequent changes in the basic assumptions ${ }^{5}$ resulted in the absence of large-scale computer implementations that incorporate insights from Mainstream Generative Grammar. There are some implementations that borrow from GB/MP models or from ideas from Mainstream Generative Grammar (Petrick 1965; Zwicky et al. 1965; Friedman 1969; Friedman et al. 1971; Morin 1973; Marcus 1980; Abney and Cole 1986; Kuhns 1986; Correa 1987; Stabler 1987,

\footnotetext{
${ }^{4}$ See, for instance, (Kuhns 1986, p. 550), (Crocker and Lewin 1992, p. 508), (Kolb and Thiersch 1991, p. 262), and (Kolb 1997, p. 3) on precision; and (Freidin 1997, p. 580), (Veenstra 1998, p. 25, 47), (Lappin et al. 2000, p. 888), and (Stabler 2010, p. 397, 399, 400) on missing details.

${ }^{5}$ See, for instance, (Kolb 1997, p. 4), (Fanselow 2009), and the quote by Stabler on p. 37.
} 
1992, 2001; Kolb and Thiersch 1991; Fong 1991; Crocker and Lewin 1992; Lohnstein 1993; Fordham and Crocker 1994; Nordgård 1994; Veenstra 1998; Niyogi and Berwick 2005), but these implementations usually do not employ transformations or deviate in other crucial ways from theoretical work. See (Kay 2011, p. 10) for discussion of early transformational systems, and (Müller 2013a, Section 3.7.2; Müller 2015b, Section 3.7.2) for further discussion of GB and Minimalist systems.

There are two implementations that can be regarded as implementations of Minimalist ideas. I will comment on them briefly: Stabler (2001) shows how Kayne's theory of remnant movement can be formalized and implemented. However, his implementation does not use transderivational constraints, does not have numerations, has no Agree (see Fong 2014, p.132), and so on. Stabler's grammars are small-scale fragments that can be considered proofs of concept, but nothing more. They only deal with syntax; there is no morphology ${ }^{6}$, no treatment of multiple agreement (Stabler 2011, Section 27.4.3), and no semantics; and neither PF nor LF processes are modeled. ${ }^{7}$ Another implementation that uses Minimalist Grammar as a framework is the one of Niyogi and Berwick (2005). This grammar has 347 lexical entries and covers a lot of argument alternations. It is probably the largest implementation of Minimalist ideas. However, it differs from theoretical proposals in not using numerations, in having six or seven (if OPTIONAL MERGE is counted) rules for combination of material rather then just internal and external merge, and in not using labelling but rather a Categorial Grammar-like functor argument approach. In (Berwick et al. 2011), a later paper that explicitly discusses computer implementations, this system is not mentioned.

${ }^{6}$ The test sentences have the form in (i).

(i) a. the king will -s eat

b. the king have -s eat -en

c. the king be -s eat -ing

d. the king -s will -s have been eat -ing the pie

${ }^{7}$ See, for instance, (Sauerland and Elbourne 2002, p. 285) for suggestions on $\mathrm{PF}$ and LF movement that includes the deletions of parts of copies. The implementation of such analyses is probably non-trivial. 
The grammars and the processing system developed by Sandiway Fong (Fong and Ginsburg 2012; Fong 2014) have a similar status: The grammar fragments are small, encode syntactic aspects like Labeling directly in the phrase structure rules (Fong and Ginsburg 2012, Section 4), and hence fall far behind $\overline{\mathrm{X}}$ Theory. The grammars do not have a morphology component, and Spell-Out is not implemented; therefore, this system neither parses nor generates a single sentence from any natural language. ${ }^{8}$

The reason for the absence of large-scale fragments in the framework of GB/MP is probably that the basic assumptions that are made in the Minimalist community are changing very frequently:

In Minimalism, the triggering head is often called a probe, the moving element is called a goal, and there are various proposals about the relations among the features that trigger syntactic effects. Chomsky (1995, p. 229) begins with the assumption that features represent requirements which are checked and deleted when the requirement is met. The first assumption is modified almost immediately so that only a proper subset of the features, namely the 'formal', 'uninterpretable' features are deleted by checking operations in a successful derivation (Collins, 1997; Chomsky 1995, §4.5). Another idea is that certain features, in particular the features of certain functional categories, may be initially unval-

\footnotetext{
${ }^{8}$ The following claim by Berwick et al. (2011, p. 1221) is therefore simply wrong: But since we have sometimes adverted to computational considerations, as with the ability to "check" features of a head/label, this raises a legitimate concern about whether our framework is computationally realizable. So it is worth noting that the copy conception of movement, along with the locally oriented "search and labeling" procedure described above, can be implemented computationally as an efficient parser; see Fong, 2011, for details. One cannot claim that one has an efficient implementation if the software under consideration does not parse any sentence at all, since it might be possible that the implementation of the missing parts is extremely complex and the resulting program would be inefficient. As was noted above, Fong does not implement Labeling as it was introduced in Chomsky's papers (for instance, Chomsky 2008, 2013), but simply uses definite clause grammars. In fact, neither of the two Chomsky papers is implementable, since the description of Labeling is not worked out in detail. Crucial cases are missing in the 2008 paper and the 2013 paper is vague in some places and inconsistent in others (Müller 2013c).
} 
ued, becoming valued by entering into appropriate structural configurations with other elements (Chomsky 2008; Hiraiwa, 2005). And some recent work adopts the view that features are never deleted (Chomsky 2007, p. 11). These issues remain unsolved. (Stabler 2010, p. 397)

Developing a grammar fragment takes at least three years. Large grammars accumulate the knowledge of several researchers which has crystallized in international cooperations over the course of several years or even decades. However, such a process is blocked when basic assumptions are changed frequently (see also Fanselow 2009, p. 138).

The same criticism that applies to GB/Minimalism applies to Construction Grammar: The basic notions and key concepts are hardly ever made explicit with the exception of Sign-Based Construction Grammar (Sag 2010, 2012), which is an HPSG variant, Embodied Construction Grammar (Bergen and Chang 2005), which uses feature value matrices and is equivalent to HPSG (see Müller 2010a, Chapter 9.6, for a discussion of both theories), and Fluid Construction Grammar (Steels 2011). ${ }^{9}$

\section{AND MOTIVATION OF ANALYSES}

In this section, I first describe recent advances in research on language acquisition and then show how the data-driven, bottom-up approach to theory development that is followed in the CoreGram project works in detail.

As is argued in (Müller 2010a, Chapter 11.4) and (Müller 2015b, Chapter 12.4), HPSG is compatible with UG-based models of language acquisition such as, for instance, the one by Fodor (1998). See (Fodor

${ }^{9}$ Steels (2013, p. 153) sees Fluid Construction Grammar as a toolkit for the implementation of various Construction Grammar ideas. So in this view, it would not be a theory or framework but rather a system such as TRALE or LKB, which are discussed below. Van Trijp (2013, 2014) sees Fluid Construction Grammar as a framework and compares it with HPSG. For a detailed discussion of specific analyses formalized in Fluid Construction Grammar and van Trijp's core assumptions, see (Müller 2015b, Section 9.6.4). 
2001, p. 385) for an explicit remark to that end. However, in recent years evidence has accumulated showing that arguments for innate, language-specific knowledge are very weak. For instance, Johnson (2004) showed that Gold's (1967) proof that natural languages are not identifiable in the limit by positive data alone is irrelevant for discussions of human language acquisition. Furthermore, there is evidence that the input that humans have is sufficiently rich to acquire structures which were thought by Chomsky (1971, p. 29-33; 2013, p. 39) and others to be impossible to acquire: Bod (2009) showed how syntactic structures could be derived from an unannotated corpus by Unsupervised Data-Oriented Parsing. He assumed that language is organized in chunks, and it has been described how children can acquire the fact that linguistic expressions are combined from smaller parts into larger units (see Estigarribia 2009 for acquisition of fragments starting at the right periphery of utterances). Given this prerequisite, Bod explained how Chomsky's auxiliary inversion data can be captured even if the input does not contain the data that Chomsky claims to be necessary (see also Eisenberg 1992, Pullum and Scholz 2002, and Scholz and Pullum 2002 for other Poverty of the Stimulus arguments). Input-based models of language acquisition in the spirit of Tomasello (2003) seem highly promising and can, in fact, explain language acquisition data better than previous UG-based models (Freudenthal et al. 2006, 2009). I have argued that the results from language acquisition research in the Construction Grammar framework can be carried over to HPSG, even in its lexical variants (Müller 2010a, 2015b; Müller and Wechsler 2014, Section 9). ${ }^{10}$ If language acquisition is inputbased and language-specific innate knowledge is minimal, as assumed by Chomsky (1995) and Hauser et al. (2002), or even non-existing, this has important consequences for the construction of linguistic theories: Proposals that assume more than 400 morpho-syntactic categories that are all innate and that play a role in all languages of the world, even though they are not directly observable in many languages (Cinque

\footnotetext{
${ }^{10}$ In fact, I believe that a lexical treatment of argument structure is the only one that is compatible with the basic tenets of theories like Categorial Grammar (CG), Lexical Functional Grammar (LFG), Construction Grammar, and HPSG that adhere to lexical integrity (Bresnan and Mchombo 1995). For discussion, see (Müller 2006), (Müller 2010a, Chapter 11.11), (Müller 2010b), (Müller 2013c), and (Müller and Wechsler 2014).
} 
and Rizzi 2010, p.55, 57), have to be rejected right away. Furthermore, one cannot argue for empty functional projections in language $\mathrm{X}$ on the basis of overt morphemes in language Y. This has, for instance, been done for Topic projections that are assumed for languages without topic morphemes on the basis of the existence of a topic morpheme in Japanese and Gungbe. Similarly, functional projections for object agreement (AgrO) have been proposed for languages like English and German on the basis of Basque data, even though neither English nor German has object agreement. Since German children do not have any evidence from Basque, they would not be able to learn that there are projections for object agreement, and hence this fact would have to be known in advance. Neither can the existence of postpositions and agreement in Hungarian be seen as evidence for AgrO projections and hidden movement processes in English as assumed in the analysis by Hornstein et al. (2005, p. 124). Such complicated analyses cannot be motivated language-internally and hence are not acquirable from input alone. Since there is no theory-external evidence for such projections, theories that can do without such projections and without stipulations about UG should be preferred.

However, this does not mean that the search for universals or for similarities between languages and language classes is fundamentally misguided, although it may be possible that there is very little that is truly universal (Evans and Levinson 2009): ${ }^{11}$ In principle, infinitely many descriptions of a particular language exist. It is possible to write a grammar that is descriptively adequate, but the way the grammar is written does not extend to other languages. So even without making broad claims about all languages, it is useful to look at several languages, and the more they differ from each other, the better. What we try to do in the CoreGram project is the modest version of mainstream generative grammar: We start with grammars of individual languages and generalize from there. We think that the framework we are using is well-suited for capturing generalizations within a language and across languages, since inheritance hierarchies are ideal tools for this. Note though that inheritance hierarchies are not the only place in the theory where generalizations can be captured. This is discussed in more detail

${ }^{11}$ But see (Harbour 2011) and the responses of authors in the same volume as Evans and Levinson's contribution for criticism of this paper. 
in Sections 2.2 and 5.1.2 below. Of course, when building grammars, we can rely on several decades of research in theoretical linguistics and build on the insights that were gained by researchers working under UG-oriented assumptions. Without a theory-driven, comparative perspective on language, certain questions would never have been asked, and it is good that we have such valuable resources at hand. We nevertheless see some developments rather critically, as should be clear from the statements I have made above.

Data-driven, bottom-up theory development

Instead of imposing constraints from one language onto other languages, a bottom-up approach seems to be more appropriate: Grammars for individual languages should be motivated language-internally. Grammars that share certain properties can be grouped in classes. This makes it possible to capture generalizations about groups of languages and language as such. Let us consider some examples: German, Dutch, Danish, English and French. If we start developing grammars for German and Dutch, we find that they share a lot of properties: both are SOV and V2 languages, both have a verbal complex. One main difference is the order of elements in the verbal complex. The situation can be depicted as in Figure 3. There are some properties that are shared between German and Dutch (Set 3). For instance, the argument structure, a list containing descriptions of syntactic and semantic properties of arguments, and the linking of these arguments to the meaning of the sign is contained in Set 3. In addition, the constraints for SOV languages, the verb position in V2 clauses, and the fronting of a constituent in V2 clauses are contained in Set 3. The respective constraints are shared between the two grammars. When we

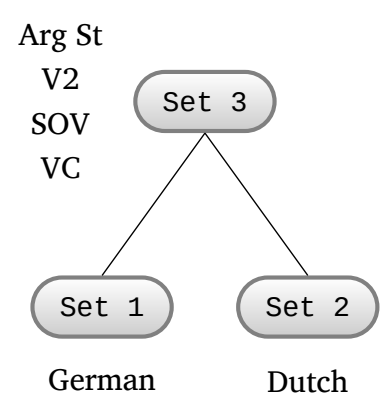

Figure 3:

Shared properties of German and Dutch 
Figure 4:

Shared

Properties of German, Dutch, and Danish

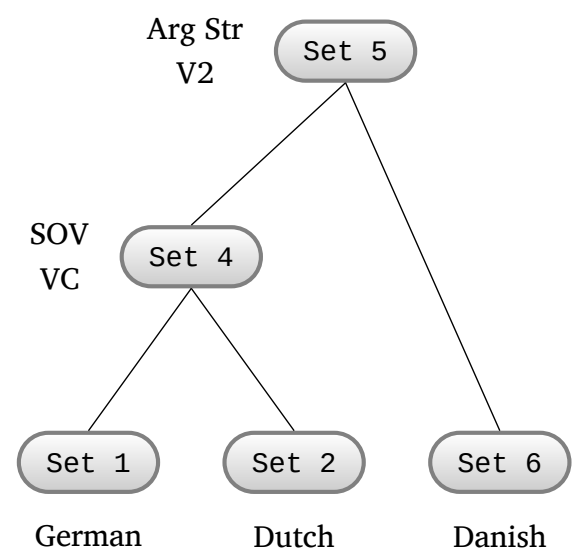

add another language, say Danish, we get further differences. While German and Dutch are SOV, Danish is an SVO language.

Figure 4 shows the resulting situation: The top-most node represents constraints that hold for all the languages considered so far (for instance, the argument structure constraints, linking, and V2), and the node below it (Set 4) contains constraints that hold for German and Dutch only. For instance, Set 4 contains constraints regarding verbal complexes and SOV order. In principle, there could be constraints that hold for Dutch and Danish but not for German, and for German and Danish but not for Dutch. These constraints would be removed from Set 1 and Set 2 respectively and put into another constraint set higher up in the hierarchy. For clarity, these sets are not illustrated in the figure, and I keep the names Set 1 and Set 2 from Figure 3 for the constraint sets for German and Dutch. The union of Set 4 and Set 5 is Set 3 of Figure 3.

If we add further languages, further constraint sets will be distinguished. Figure 5 on the facing page shows the situation that results when we add English and French. Again, the picture is not complete since there are constraints that are shared by Danish and English but not by French, but the general idea should be clear: By systematically working this way, we should arrive at constraint sets that directly correspond to those that have been established in the typological literature.

It should be clear from what has been said so far that the goal of every scientist who works this way is to find generalizations and 


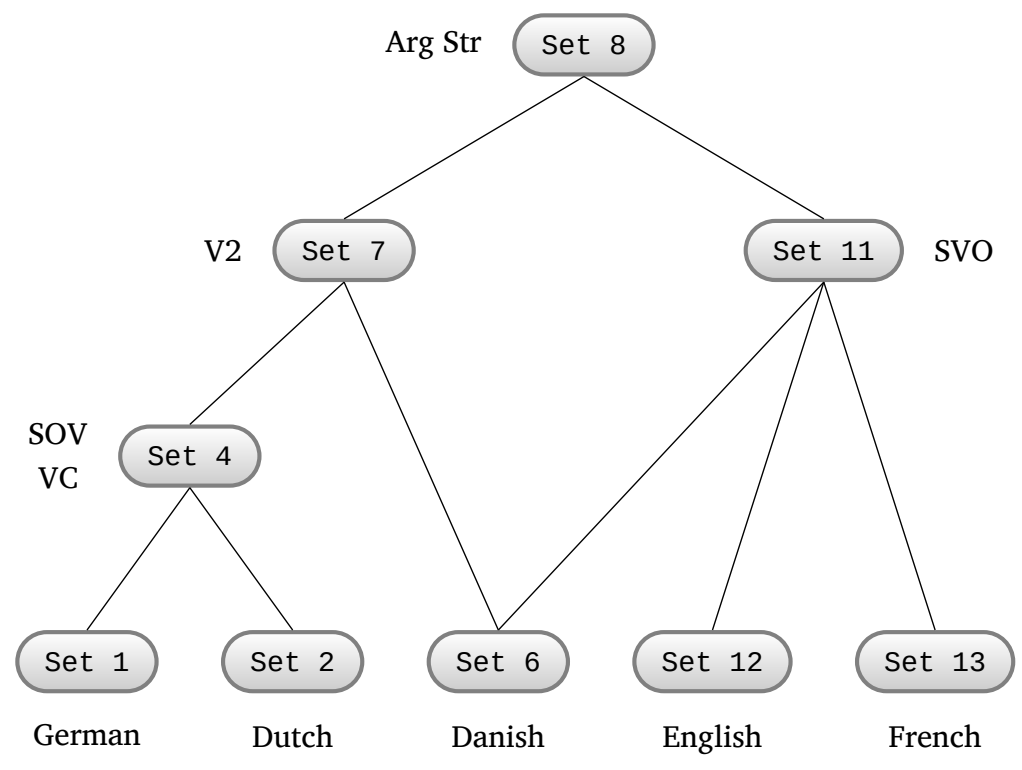

to describe a new language in a way that reuses theoretical constructs that have been found useful for a language already covered. However, as was explained above, the resulting grammars should be motivated by data of the respective languages and not by facts from other languages. In situations where more than one analysis would be compatible with a given dataset for language $\mathrm{X}$, the evidence from language $\mathrm{Y}$ with similar constructs is most welcome and can be used as evidence in favor of one of the two analyses for language X. I call this approach the bottom-up approach with cheating: Unless there is contradicting evidence, we can reuse analyses that have been developed for other languages.

Note that this approach is compatible with the rather agnostic view advocated by Haspelmath (2010a), Dryer (1997), Croft (2001, Section 1.4.2-1.4.3), and others, who argue that descriptive categories should be language-specific, that is, the notion of subject for Tagalog is different from the one for English, the category noun in English is different from the category noun in Persian, and so on. Even if one follows such extreme positions, one can still derive generalizations regarding constituent structure, head-argument relations and so on. However, I believe that some categories can fruitfully be used cross-linguistically - if not universally, then at least for language
Figure 5:

Languages and language classes 
classes. As Newmeyer (2010, p. 692) notes with regard to the notion of subject: Calling two items subject in one language does not entail that they have identical properties. The same is true for two linguistic items from different languages: calling a Persian linguistic item subject does not entail that it has exactly the same properties as an English linguistic object that is called subject. The same is, of course, true for all other categories and relations, for instance, parts of speech: Persian nouns do not share all properties with English nouns. ${ }^{12}$ Haspelmath (2010b, p. 697) writes: Generative linguists try to use as many crosslinguistic categories in the description of individual languages as possible, and this often leads to insurmountable problems. If the assumption of a category results in problems, they have to be solved. If this is not possible with the given set of categories or features, new ones have to be assumed. This is not a drawback of the methodology, quite the opposite: If we have found something that does not integrate nicely into what we already have, this is a sign that we have discovered something new and exciting. If we stick to language-particular categories and features, it is much harder to notice that a special phenomenon is involved since all categories and features are specific to one language anyway. Note also that not all speakers of a language community have exactly the same categories. If one were to take the idea of language-particular category symbols to an extreme, one would end up with person-specific category symbols like Kim-English-noun.

\footnotetext{
${ }^{12}$ Note that using labels like Persian Noun and English Noun is somewhat strange since it implies that both Persian nouns and English nouns are nouns in some way (see, for instance, Haspelmath 2010a, Section 2, for such a suggestion regarding case, e. g. Russian Dative, Korean Dative, ...). Instead of using the category Persian Noun one could assign objects of the respective class to the class noun and add a feature LANGUAGE with the value persian. This simple trick makes it possible to assign both objects of the type Persian Noun and objects of the type English Noun to the class noun and still maintain the fact that there are differences. Of course, no theoretical linguist would introduce the LANGUAGE feature to differentiate between Persian and English nouns, but nouns in the respective languages have other features that make them differ. So, the part-ofspeech classification as noun is a generalization over nouns in various languages and the categories Persian Noun and English Noun are feature bundles that contain further, language-specific information.
} 
After a talk I gave at the MIT in 2013, members of the linguistics department objected to the approach taken in the CoreGram project and claimed that it would not make any predictions as far as possible or impossible languages are concerned. Regarding predictions, two things must be said: Firstly, predictions are being made on a languageparticular basis. As an example, consider the following sentences from (Netter 1991):

(5) a. [Versucht, zu lesen], hat er das Buch nicht. tried to read has he the book not 'He did not try to read the book.'

b. [Versucht, einen Freund vorzustellen], hat er ihr noch tried a friend to.introduce has he her yet nie. never

'He never tried to introduce her to a friend.'

When I first read these sentences, I had no idea about their structure. I typed them into my computer, and within milliseconds, got a syntactic analysis. When I studied the results, I realized that these sentences are combinations of partial verb phrase fronting and the socalled third construction (Müller 1999, p. 439). I had previously implemented analyses of both phenomena, but had never thought about the interaction of the two. The grammar predicted that examples like (5) are grammatical. Similarly, the constraints of the grammar can interact to rule out certain structures. So, predictions about ungrammaticality or impossible structures are in fact made as well.

Secondly, the top-most constraint set holds for all languages seen so far. It can be regarded as a hypothesis about properties that are shared by all languages. This set contains constraints for the connection between syntax and information structure, and such constraints allow for V2 languages but rule out languages with the verb in penultimate position. (See Kayne 1994, p. 50, for the claim that such languages do not exist. Kayne develops a complicated syntactic system that predicts this.) Of course, if a language is found that puts the verb in penultimate position for the encoding of sentence types or some other communicative effect, a more general top-most set has to be defined, but this is parallel for Minimalist theories: If languages are found that are incompatible with basic assumptions, the basic assumptions 
have to be revised. As with the language particular constraints, the constraints from the top-most set make certain predictions about the phenomena that can and cannot be found in languages.

Cinque (1999, p. 106) suggested a cascade of functional projections to account for reoccurring orderings in the languages of the world. He assumes elaborate tree structures to play a role in the analysis of all sentences in all languages, even if there is no evidence for respective morphosyntactic distinctions in a particular language (see also Cinque and Rizzi 2010, p. 55). In the latter case, Cinque assumes that the respective tree nodes are empty. Cinque's results could be incorporated in the model advocated here. We would define part-ofspeech categories and morpho-syntactic features in the top-most set, and state linearization constraints that enforce the order that Cinque encoded directly in his tree structure. In languages in which such categories are not manifested by lexical material, the constraints would never apply. Neither empty elements nor elaborate tree structures would be needed. So, Cinque's data could be covered in a better way in an HPSG with a rich UG. However, we refrain from assuming a rich UG and introducing 400 categories (or features) into the theories of all languages. Again, I would like to point out that this would be implausible from a genetic point of view, and I wait for other, probably functional, explanations of the Cinque data.

Frequently discussed examples, such as those languages that form questions by reversing the order of the words in a string (Musso et al. 2003), need not be ruled out in the grammar since they are ruled out by language external constraints: We simply do not have enough working memory to do such complex computations.

After having justified the basic approach taken in the CoreGram project, I now turn to the coverage of the grammars and discuss some highlights.

The computer-processable grammar fragments of German, Persian, and Danish are relatively big. ${ }^{13}$ The German grammar (BerliGram)

\footnotetext{
${ }^{13} \mathrm{~A}$ list of covered phenomena accompanied by appropriate grammatical and ungrammatical test strings is part of the distributions of the grammars and
} 
was the first one to be implemented. It is an extension of the grammars that were developed for the individual chapters of the HPSG textbook (Müller 2007b). The textbook covers noun phrases with adjuncts (APs, PPs, relative clauses), determinerless NPs, constituent order (scrambling, verb position and clause types, nonlocal dependencies for fronting), agreement (subject-verb and NP internal), predicate complex formation (verbal complexes and adjective-verb complexes, Oberfeldumstellung, partial fronting), control and raising, case assignment and passive (personal, impersonal, remote passive, attributive participles, lassen passive, bekommen passive, state passive, modal infinitives), particle verbs (productive and lexicalized), morphology (inflectional and derivational, for instance -bar 'able' derivation), and (symmetric) coordination. The Situation Semantics that is used in the textbook was replaced by a Minimal Recursion Semantics (MRS, Copestake et al. 2005). MRS allows for underspecification of scope, so that a sentence like (6) gets one representation from which the several scopings can be derived. See (Dowty 1979, Section 5.6) for the discussion of the readings of again in English, and (Egg 1999) for the explanation of the different readings of (6).

(6) a. dass Max wieder alle Fenster öffnete that Max again all windows opened 'that Max opened all windows again'

b. again' $^{\prime}\left(\forall\left(\operatorname{CAUSE}\left(\right.\right.\right.$ open $\left.\left.\left.^{\prime}\right)\right)\right)$; repetitive

c. $\operatorname{again}^{\prime}\left(\mathrm{CAUSE}\left(\forall\left(\right.\right.\right.$ open $\left.\left.\left.^{\prime}\right)\right)\right)$; repetitive

d. CAUSE(again' $\left(\forall\left(\right.\right.$ open $\left.\left.\left.^{\prime}\right)\right)\right)$; restitutive

Von Stechow (1996, p. 93) develops an analysis in the framework of Minimalism that assumes an empty VOICE head that contributes the CAUSE relation and some further functional heads for AgrO and AgrS. The empty heads were used to derive several readings in a movementbased analysis. However, as Jäger and Blutner (2003) pointed out, von Stechow's analysis cannot derive all readings. We therefore follow Egg (1999) and treat (6a) as an instance of sublexical scoping: öffnen is lexically decomposed into CAUSE(open'), and the again can scope below the CAUSE operator although there is no decomposition in syntax. The

can be downloaded at the respective web pages: http://hpsg.fu-berlin.de/ Projects/CoreGram.html. 
scope relations are represented in dominance graphs. Egg's analysis has been translated into MRS (see Müller 2010a, Section 19.9.2, and Müller 2015c, Section 3). Since there is no decomposition in syntax, our analysis avoids empty elements: It is just the words of (6a) that are combined in an analysis, and only these words contribute to the interpretation.

In addition to the modification of the semantics component, some further special phenomena have been implemented. For instance, an analysis of multiple frontings (Müller 2003a), something that is unique among existing HPSG implementations. For a discussion of approaches to constituent order that are incompatible with the multiple frontings data, see (Müller 2005, 2015a). Furthermore, analyses of depictives (Müller 2008), left dislocation, copula constructions (Müller 2012), and positional expletives (Müller and Ørsnes 2011) were added. Some phenomena that have been covered in my earlier grammars of German have not yet been transferred to BerliGram.

The Danish grammar is documented in a book of more than 500 pages, which is not complete yet. The grammar covers the NP (definite marking by suffix, bare plurals, adjuncts), verb position (SVO, but verb inversion in V2 sentences), negation preposing, questions, predicational constructions, specificational constructions, agreement, coordination, case assignment, passive, perfect, adverbial phrases, embedded interrogative clauses, object shift and negation shift, partial fronting, raising and control, passive (personal and impersonal constructions) and complex passive, adjectival passives, preposition stranding, and modal verbs. The following examples show in a compact way the interaction of several phenomena: passive with promotion of either the direct object or the indirect object (7a,c), passive and pronoun shift $(7 \mathrm{~b}, \mathrm{~d})$, and partial fronting and object shift $(7 \mathrm{~b}, \mathrm{~d})$ :

(7) a. Bjarne bliver ikke anbefalet den. Bjarne.NOM is not recommended it.ACC 'It is not recommended to Bjarne.' (lit: 'Bjarne is not recommended it.')
b. ? Anbefalet
bliver Bjarne
den ikke.
recommended is
Bjarne.NOM it.ACC not
'It is not recommended to Bjarne.' 

c. Bogen bliver ikke anbefalet ham. book.DEF.NOM is not recommended him.ACC 'The book is not recommended to him.'
d. ? Anbefalet
bliver bogen
ham ikke. recommended is book.DEF.NOM him.ACC not 'The book is not recommended to him.'

The examples in $(7 \mathrm{~b}, \mathrm{~d})$ are interesting since Danish differs from German and Dutch in not allowing incomplete category fronting in general. Such partial frontings can only be found if the missing components are shifted pronouns, that is, pronouns to the left of the negation (Holmberg 1999). Due to the complexity of the construction, examples are marked, but Müller and Ørsnes (2013b) and Müller and Ørsnes (2015) provide attested data.

The Mandarin Chinese grammar was implemented with the help of Jia Zhongheng. We used the description in (Li and Thompson 1981) as the basis for our implementation. Currently, we cover the NP (classifiers, determiners, attributive phrases with adjectives and relative clauses), location words and localizer phrases, basic clause structure, passive (bei construction), the ba construction, adverbials (PPs, adverbs), negation, auxiliaries, aspect marking, reduplication, presentational constructions, and serial verb constructions. Among the things that are special are NPs that contain classifiers, as in (8), and change of part of speech by reduplication, as in (9).

\section{(8) 那 辆 红 的车 锈了。 na4 liang4 hong2 de che1 xiu4.le that CL red DE car rust.ASP 'That red car rusts.'}

The adjective 高兴 (gao1xing4, 'happy') in (9a) is converted into an adverb by forming the pattern $A A B B$ from the original adjective $A B$, that is, both gao1 and xing 4 are doubled. 


\section{b. 他 高高兴兴游泳。 \\ ta1 gao1gao1xing4xing4 you3yong3 \\ he $\mathrm{AABB}=$ happily swims \\ 'He swims happily.'}

The Persian grammar is a larger fragment, which still needs to be fully documented (Müller et al. In Preparation). A description of some parts of the grammar can be found in (Müller and Ghayoomi 2010). The grammar covers various types of light verb constructions, which are crucial for the analysis of Persian, since Persian has only very few verbs. The light verb constructions interact with other constructions like negation, all tenses (periphrastic and synthetic), and cliticization. All of these interactions are covered. Furthermore, the grammar contains analyses of passive, adjectival passives, the NP structure (ezafe construction, possessives, adjectives, ...), direct object marking, agreement, pro-drop, non-local dependencies including those with resumptive pronouns, inflectional and derivational morphology, coordination, relative clauses including free relative clauses, and questions.

The grammar can be used with Persian script or with a romanized version that is usually used in linguistic texts. The examples in (10) show light verb constructions, which are an important feature of the language. (10a) shows that the future auxiliary can interrupt the preverb-verb sequence of light verbs. (10b) shows an example with the negation prefix in the middle of the light verb construction and pro-drop.

a. من اين كار را انجام خواهم داد.

man in kār rā anjām xāh-am dād. ${ }^{14}$

I this job DOM performance will-1SG gave 'I will do this work.'

b. . مرد را دوست نداشت

mard rā dust na-dāšt.

man DOM friend NEG-had

'He/she did not love the man.'

The Maltese grammar is an implementation of the description by Fabri (1993). Fabri works in the framework of Lexical Decomposition Grammar, which is also a lexical framework, and his analyses are

${ }^{14}$ Example taken from (Karimi-Doostan 1997, p. 73). 
translatable into HPSG without great effort. The grammar covers basic sentence structure, pro-drop, clitics (with correct spelling and modeling of the morphophonological changes, see Section 5.1.5), adjectival predication (without copula), agreement, NP structure (including adjective order, which depends on the class of adjective), definiteness marking, and case assignment. The examples in (11) show definiteness marking. (11b) shows assimilation and (11c) shows clitics: ${ }^{15}$

a. Il-komunist xejjer lil-l-papa. DEF-communist waves.3M.SG Case-DEF-pope.M.SG 'The communist waves at the pope.'

b. It-terrorist baghat l-ittr-a lil-l-president. DEF-terrorist sent DEF-letter-F Case-DEF-president 'The terrorist sent the president the letter.'

c. It-terrorist baghat $=h i e=1$. DEF-terrorist sent.3M.SG $=3 \mathrm{~F} . \mathrm{SG}=3 \mathrm{M} . \mathrm{SG}$ 'The terrorist sent it to him.'

(11c) is ambiguous, as there is a reading with clitic left dislocation. Both readings are accommodated by the grammar.

The grammars of Yiddish, English, and Hindi are small-scale. They cover the basic structures of these languages and were implemented in connection with work comparing several languages. For instance, Yiddish covers V2 in main and embedded clauses, positional expletives (Müller and Ørsnes 2011), and embedded interrogative clauses. English covers NP structures, the main clause structure, case assignment, agreement, auxiliary verb constructions, negation, coordination, and inflectional and derivational morphology (-able derivation).

Among the basic clause structures, the grammar of Hindi covers case assignment, agreement, verbal complex formation, nonlocal dependencies, adjunctions, information structure markings, and inflectional morphology.

${ }^{15}$ The examples are taken from (Fabri 1993, p. 130). 
In the CoreGram project, we assume that valence is represented in a uniform way across languages. ${ }^{16}$ Arguments of a head are represented in the ARG-ST list (Pollard and Sag 1994, Chapter 9). They are mapped to the valence features SPR and COMPS in a language-dependent fashion. For instance, English and Danish map the subject to the SPR list and the other arguments to COMPS. Danish inserts an expletive in cases in which there is no element that can be mapped to SPR, while English does not do this (Müller and Ørsnes 2013a). German differs from both languages in mapping all arguments of finite verbs to the COMPS list (Pollard 1996).

The arguments in the ARG-ST list are ordered according to the obliqueness hierarchy of Keenan and Comrie (1977), which plays a role in the analysis of a variety of phenomena (for instance case assignment and depictive predicates). The elements of the ARG-ST list are linked to the semantic roles that a certain head has to fill. Since the traditional role labels like agent and patient are problematic, the CoreGram grammars adopt Dowty's proto-role approach (1991). ARG1, ARG2, and so on are used as role labels.

4.2

Constituent structure and constituent order

Originally, HPSG came with very few immediate dominance schemata: Head-Complement Schema, Head-Specifier Schema, Head-Adjunct Schema, the Head-Filler Schema for binding off unbounded dependencies, and the Head-Extra Schema for binding off clause-bound nonlocal dependencies. Since (Sag 1997), many HPSG analyses have a more constructional flavor, that is, specific subconstructions of these general schemata are introduced (Sag 2010). In the CoreGram project we stay within the old tradition of HPSG and continue to use the rather abstract dominance schemata. However, it is possible to state further constraints on the respective structures. So, rather than having several very specific instances of the Head-Filler Schema, we have

\footnotetext{
${ }^{16}$ Koenig and Michelson (2012) argue for an analysis of Oneida (a Northern Iroquoian language) that does not include a representation of syntactic valence. If this analysis is correct, syntactic argument structure would not be universal, but would be characteristic for a large number of languages.
} 
very few (for instance, for verb-second clauses and relative clauses) and formulate additional implicational constraints that constrain actual instances of head-filler phrases further if the antecedent of the implicational constraint is true. An example of such a constraint is the following one, which was suggested by Bildhauer and Cook (2010, p. 75):

$$
\begin{gathered}
{\left[\begin{array}{l}
\text { NON-HEAD-DTRS }\langle[\text { HEAD } \mid \text { DSL local }]\rangle \\
\text { head-filler-phrase }
\end{array}\right] \Rightarrow} \\
{\left[\begin{array}{l}
\text { IS pres } \vee \text { a-top-com } \vee \ldots .
\end{array}\right]}
\end{gathered}
$$

The constraint says that, for all head-filler phrases that have a nonhead daughter whose DSL value is of type local, the value of the information structure feature is has to be pres $\vee$ a-top-com $\vee \ldots . .{ }^{17}$

Since the schemata are rather general, they can be used for all languages under consideration so far. Of course, the languages differ in terms of constituent order, but this can be dealt with by using linearization rules that are sensitive to features whose values are language specific. For instance, all heads have a feature INITIAL. The value is ' + ', if the head has to be serialized before its complements, and '-' if it follows its complements. German and Persian verbs are INITIAL -, while English, Danish, Mandarin Chinese and Maltese verbs are INITIAL + .

We assume binary branching structures, and hence we get the structures in (13) for English and the corresponding German example:

a. He [[gave the woman] a book].

b. er [der Frau [ein Buch gab]] he the woman a book gave

The LP rules enforce that gave is linearized before the woman and gave the woman is linearized before $a$ book.

The scrambling of arguments is accounted for by ID schemata that allow the combination of a head with any of its arguments independently of the position an element has in the valence list of its head. Similar analyses have been suggested in the framework of HPSG by

${ }^{17}$ pres is an abbreviation for presentational and a-top-com abbreviates assessedtopic-comment. For further details see (Bildhauer and Cook 2010). 
Gunji (1986) for Japanese and Pollard (1996) for German. Many authors assume a valence set rather than a list. However, the order of the elements has to be represented somewhere in the grammar, since it is relevant for various phenomena. The proposal adopted in the CoreGram project assumes an ordered list but allows the saturation in an arbitrary order. For non-HPSG analyses that are similar to the setbased approaches, see (Fanselow 2001) and (Steedman and Baldridge 2006).

Non-scrambling languages like English combine heads with their complements in a strict order: The least oblique element is combined with the head first and then the more oblique complements follow. Non-scrambling languages with head-final order take the last element from the valence list first. Again, see (Steedman and Baldridge 2006) for a similar proposal in the framework of Categorial Grammar.

\section{Morphology and lexical rules}

We follow a lexical rule-based approach to morphology. Lexical rules are basically unary branching trees that license new lexical items (Briscoe and Copestake 1999; Meurers 2001). ${ }^{18} \mathrm{~A}$ lexical rule can add to or subtract from the phonology (or, in implementations, the orthography) of an input item. For instance, it is possible to analyze the complex morphological patterns that we observe in Semitic languages by mapping a root consisting of consonants to a full-fledged stem or word that has the appropriate vowels inserted. We follow Bresnan and Mchombo (1995) in assuming the Lexical Integrity Principle. This means that all morphological combinations have to be done by lexical rules, that is, fully inflected forms are part of the lexicon, most of them being licensed by productive lexical rules.

Lexical rules do not have to change the phonology or orthography of the item they apply to. For instance, lexical rules can be used to license further lexical items with extended or reduced valence requirements. As was argued in (Müller 2002, 2006) resultative constructions should be treated lexically. So, there is a lexical rule that maps the stem fisch- of the intransitive version of the verb fischen ('to fish') onto

${ }^{18}$ Goldberg (2013) calls such lexical rules lexical templates and sets them apart from lexical rules that relate stored lexical items. 
a stem fisch- that selects for a secondary predicate (adjective or PP) and the subject of this predicate as well.

(14) Er fischt den Teich leer. he fishes the pond empty

Semantics

All grammars come with a semantics component. We use Minimal Recursion Semantics (Copestake et al. 2005), since it allows for the underspecification of scope (see Section 3). For instance, the sentence in (15) has two readings: one in which the existential quantifier outscopes the universal quantifier and one in which the scopings are reversed.
a. Every dog chased some cat.
b. $\forall x(\operatorname{dog}(x) \rightarrow \exists y(\operatorname{cat}(y) \wedge \operatorname{chase}(x, y)))$
c. $\exists y(\operatorname{cat}(y) \wedge \forall x(\operatorname{dog}(x) \rightarrow \operatorname{chase}(x, y)))$

These readings can be represented compactly in an underspecified way as in (16):

(16) $\langle\mathrm{h} 0$, \{

$$
\begin{aligned}
& \text { h1:every(x, h2, h3), h4:dog(x), h5:chase(e, x, y), } \\
& \text { h6:some(y, h7, h8), h9:cat(y) }\},\left\{\text { h2 }={ }_{q} \text { h4, h7 }={ }_{q} \text { h9 }\right\}
\end{aligned}
$$

Every word that contributes semantically has a referential index $(\mathrm{x}, \mathrm{y}$ in (16)) or event variable (e in (16)) and a list of relations that contains elementary predications. Elementary predications come with a so-called handle (h1, h4, h5, h6, and h9 in (16)) that can be used to embed the respective elementary predicate under another one. Quantifiers are represented as three-place predicates. They have one slot for the variable they bind and two further slots for their scope and their restriction (for instance h7 and h8 in (16)). In addition, it is possible to specify scope constraints that say which elementary predication has to be outscoped by a certain quantifier (for instance, (16) says that the h2 argument of every has to outscope h4, which is the handle of dog).

The MRS in (16) can best be depicted as in Figure 6. h0 stands for the top element. This is a handle that dominates all other handles in a dominance graph. The restriction of every dominates $d o g$ and the restriction of some dominates cat. The bodies of both quantifiers dominate chase. The interesting thing is that exact dominance relations are 


\section{Stefan Müller}

Figure 6:

Dominance graph for Every dog chases some cat.

Figure 7: $\operatorname{every}(\mathrm{x}, \operatorname{dog}(\mathrm{x})$, some(y, cat(y), chase $(\mathrm{x}, \mathrm{y}))) \equiv$

(15b)
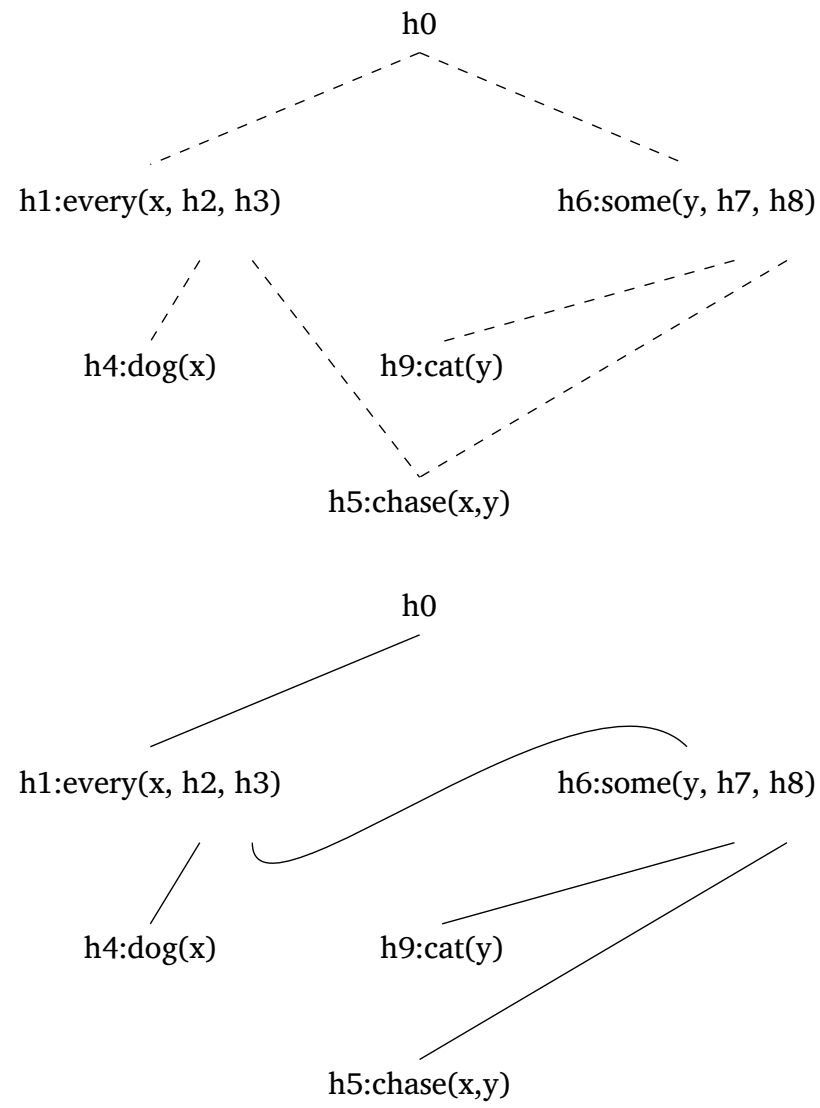

not fixed, which is indicated by the dashed lines in Figure 6. There are two ways to plug an elementary predication into the open slots of the quantifiers:

(17) a. Solution one: h0 $=\mathrm{h} 1, \mathrm{~h} 2=\mathrm{h} 4, \mathrm{~h} 3=\mathrm{h} 5$, h7 $=\mathrm{h} 9$, and $\mathrm{h} 8=\mathrm{h} 5$.

(every dog has wide scope)

b. Solution two: h0 = h6, h7 = h9, h8 = h1, h2 =h4, and h3 = h5.

(some cat has wide scope)

The solutions are depicted as Figure 7 and Figure 8.

When several linguistic objects are combined, all the elementary predications and the scope constraints are collected at mother nodes. 


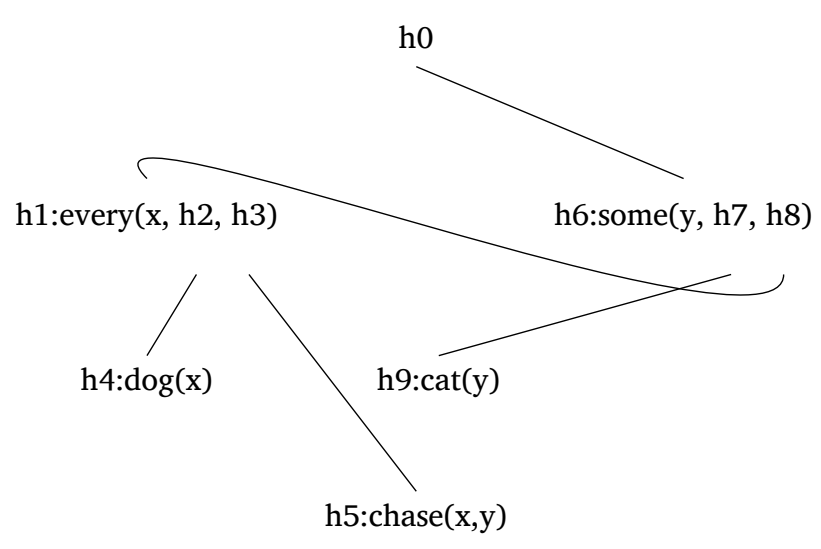

This corresponds to traditional compositional semantics. However, it is also possible to add additional relations and scope constraints in the computation of the meaning of a certain combination. This makes it possible to capture the insight from Construction Grammar that sometimes the meaning of a complex combination contains more than is present in the individual components of the complex object.

See (Copestake et al. 2005) for a full introduction to MRS, and (Müller 2015c) for a brief one.

4.5

Information structure

The German grammar contains constraints on information structure. The corresponding theory was developed by Felix Bildhauer and Philippa Cook and implemented by Felix Bildhauer in Project A6 of the collaborative research centre SFB 632 on information structure (Bildhauer and Cook 2010; Müller et al. 2012). See also Example (12) above. Project A6 explored the various contexts for so-called multiple frontings. It implemented an analysis that refers to syntactic configurations and assigns the elementary predications from an MRS representation to TOPIC and FOCUS lists. See (Engdahl and Vallduví 1996) for the general approach.

Elodie Winckel is currently augmenting the French grammar with an information-structure component. This work is also carried out in the context of SFB 632, and one goal of this work is to test to what extent it is possible to explain island constraints with respect to information structure (Ambridge and Goldberg 2008).
Figure 8:

some(y, cat(y), every $(\mathrm{x}, \operatorname{dog}(\mathrm{x})$ $\operatorname{chase}(\mathrm{x}, \mathrm{y}))) \equiv$ (15c) 
Bildhauer's (2008) Spanish grammar also implements a theory of information structure, and as was mentioned above, this grammar is currently ported to the CoreGram format.

The grammars are implemented in TRALE (Meurers et al. 2002; Penn 2004). TRALE implements typed feature descriptions. Every grammar consists of a signature (a type hierarchy with feature introduction and appropriateness constraints) and a theory that states constraints on objects of these types. TRALE is implemented in Prolog and comes with an implementation of relational constraints that maps the TRALE relations to Prolog relations. TRALE has two parsers: a standard bottom-up chart parser and a linearization parser (Suhre 1999). The CoreGram project uses the standard bottom-up parser. Both parsers use a phrase structure backbone. TRALE is available as bootable CD-ROM (Müller 2007a). The CD-ROM contains a full installation of all components that were available in 2007. This includes a chart display for developing and debugging grammars, Utool for visualizing dominance graphs from semantic representations and scope resolving (Koller and Thater 2005), and [incr tsdb()] for systematic testing (see Section 7). We hope to finish a new virtual machine soon that includes a new and much faster version of TRALE, the most recent versions of the CoreGram grammars, and Kahina, a powerful debugger for constraint resolution systems like TRALE (Dellert et al. 2010, 2013). A beta version is already available.

Compared to other systems such as LKB (Copestake 2002), the expressive power of the description language is high (see also Melnik 2007). This allows for the rather direct implementation of analyses that are proposed by theoretical linguists. The following descriptive devices are used in the theory and are provided by TRALE; the references point to papers which argue for such constructs:

- empty elements (Kiss 1995; Meurers 1999a; Levine and Hukari 2006; Bender 2000; Sag et al. 2003, p. 464; Borsley 2004, Section 3.3; Müller 2007b, 2014b,d; Haugereid et al. 2013) 
- relational constraints (Pollard and Sag 1994; Bouma et al. 2001; Meurers et al. 2003),

- complex antecedents in implicational constraints (Bonami et al. 1998; Meurers 2000, p. 207; Bonami and Godard 2001, p. 148; Koenig and Davis 2004, p. 145, 149; Müller 2007b, p. 145, Section 10.3; 2014d; Bildhauer and Cook 2010, p. 75; Van Eynde and Augustinus 2014, p. 166; Alotaibi and Borsley 2013, p. 18),

- cyclic structures (Engdahl and Vallduví 1994, p.56; Meurers, 2000, p. 2007; 2001, p. 176, Samvelian 2007, p. 638),

- macros, and

- a morphology component that has the expressive power needed to account for nontrivial morphological phenomena.

\subsubsection{Empty elements}

All CoreGram grammars use empty elements to account for extraction phenomena. Auxiliary inversion in English has not yet been implemented, but German and Danish use head-movement analyses to account for the verb in initial position in questions and V2 clauses. TRALE has mechanisms to precompile grammars and to eliminate most of the empty elements (for a discussion, see Müller 2014b).

\subsubsection{Complex antecedents}

To see how useful implicational constraints with complex antecedents are both from a theoretical and an implementational perspective, consider the constraint in (12) again. Proposals that do not make use of such implementational constraints would have to introduce two subtypes of head-filler-phrase: one for head-filler phrases with the DSL value local - let us call this type head-filler-phrase-dsl - and one for head-filler phrases with the DSL value different from local. The information structure constraints from (12) will be constraints on structures of type head-filler-phrase-dsl:

(18) head-filler-phrase-dsl $\Rightarrow$

$$
\left[\begin{array}{l}
\text { NON-HEAD-DTRS }\langle[\text { HEAD } \mid \text { DSL local }]\rangle \\
\text { Is pres } \vee \text { a-top-com } \vee \ldots
\end{array}\right]
$$

Proponents of such a theory would basically make explicit which daughters could appear in the filler position. 
In our setting with implicational constraints, we do not need these two additional types. We formulate the constraint in (12), and this constraint applies only to those head-filler phrases that have a nonhead daughter with a DSL value of type local. Therefore, our theory is simpler and has to be preferred over other approaches that duplicate information about the combinatorics of linguistic objects in type names.

5.1 .3

Relational constraints

The relational constraint that is used most often in HPSG is append $(' \oplus$ '), which concatenates two lists. While many of the uses of append can be recoded using difference lists, this is not always the case. See (Meurers et al. 2003) for some discussion. In the implementation of scrambling that was sketched in Section 4.2 above, a valence list is split into three parts. The first is a list of arbitrary length, the second is a list containing the element that has to be combined with the head, and the third is a list of arbitrary length again. This can be implemented directly using append: $\mathrm{A} \oplus\langle\mathrm{XP}\rangle \oplus \mathrm{B}$.

Another application of relational constraints is the determination of the last element of a list. For technical reasons the argument structure and valence lists are represented with the most oblique element at the beginning (as in Pollard and Sag 1987). If one wants to access the least oblique element in the ARG-ST list, one has to find the last element of this list. In the theory of Heinz and Matiasek (1994), which follows Haider (1986), transitive and unergative verbs have a designated argument that is identical to the least oblique argument of the verb. (19) shows how this can be expressed in TRALE:

(synsem:loc:cat:(head:da:[last(ArgSt)], arg_st:ArgSt))

ArgSt is the value of the ARG-ST feature, and last(ArgSt) returns the last element of this list, which is represented as the element of the list which is the value of the feature DA. Note that this works for lists of arbitrary length. This is important for verbs like the German lassen ('to let') that raise the arguments of the verbal element that they embed. TRALE uses a delay mechanism to postpone the execution of relational constraints until enough information is available. In the case of lassen, 
the constraints are delayed until it is combined with the embedded verb and the actual length of its argument structure list is known.

\section{1 .4}

Macros

Just like types, macros can be organized in hierarchies. The type hierarchies are stated in a signature, but the macro hierarchies are constructed by calling other macros in a macro definition. Macros differ from types in allowing parameters. This makes it possible to represent the lexicon in a rather compact way. For instance, (20a) shows the lexical item for work, and (20b) the definition of the macro that is called.

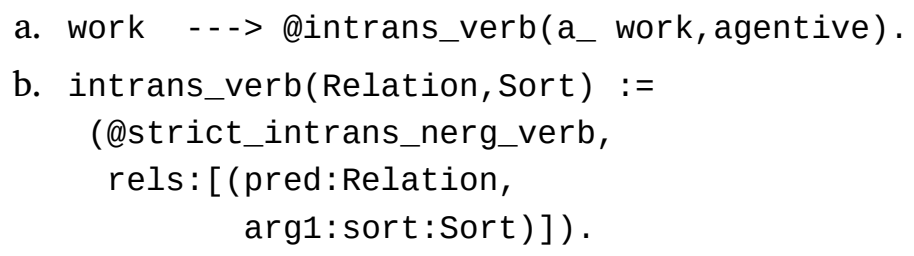

TRALE uses a special syntax for lexical rules: an identifier is followed by the keyword 'lex_rule', by the input description, the arrow '** $>$ ' and the output description. Since we want to be as close as possible to HPSG analyses, we assume that every lexical rule has a specific type (definiteness_lr in (24) below). The respective typed feature structure models a linguistic object with a daughters list. The daughter is the input of the lexical rule. In addition to this, a lexical rule has to have a morphs statement that says something about how the orthography of the input is related to the orthography of the output. (24) shows the lexical rule that is used to account for definiteness marking in Maltese. Definiteness is marked with an /l/ at nouns and adjectives in Maltese. (21) gives an example: ${ }^{19}$

\section{(21) 1-ktieb \\ DEF-book}

If the noun starts with one of the coronals $/ \mathrm{d} /, / \mathrm{t} /, / \mathrm{s} /, / \mathrm{z} /, / \mathrm{s} /, / \mathrm{ts} /$, $/ \mathrm{t} \int /, / \mathrm{n} /$, or $/ \mathrm{r} /$, the $/ \mathrm{l} /$ is assimilated. (22) gives an example:

\footnotetext{
${ }^{19}$ (21), (22) and (23b) are underlying forms. If the definite form of book is used in isolation, an /i/ has to be added.
} 
(22) r-ragel

DEF-man

The only exception is the coronal $/ \mathrm{d}_{3} /$, which is exempt from assimilation.

Inner epenthesis can be observed if the word starts with /s/ or $/ \mathrm{S} /$ followed by a consonant:
a. skola school
b. 1-iskola DEF-school

If inner epenthesis applies, it prevents assimilation.

The lexical rule splits the input characters into an initial part $S$ and a part $\mathrm{X}$ and tests whether $\mathrm{S}$ is $[\mathrm{s}]$ or $[\mathrm{x}]$ by calling the predicate s_sh. If this call succeeds, $l i$ is appended to the output. If this call does not succeed, other clauses are tried. If the input starts with a coronal, the coronal is doubled. Otherwise the input is prefixed with an $l .{ }^{20}$

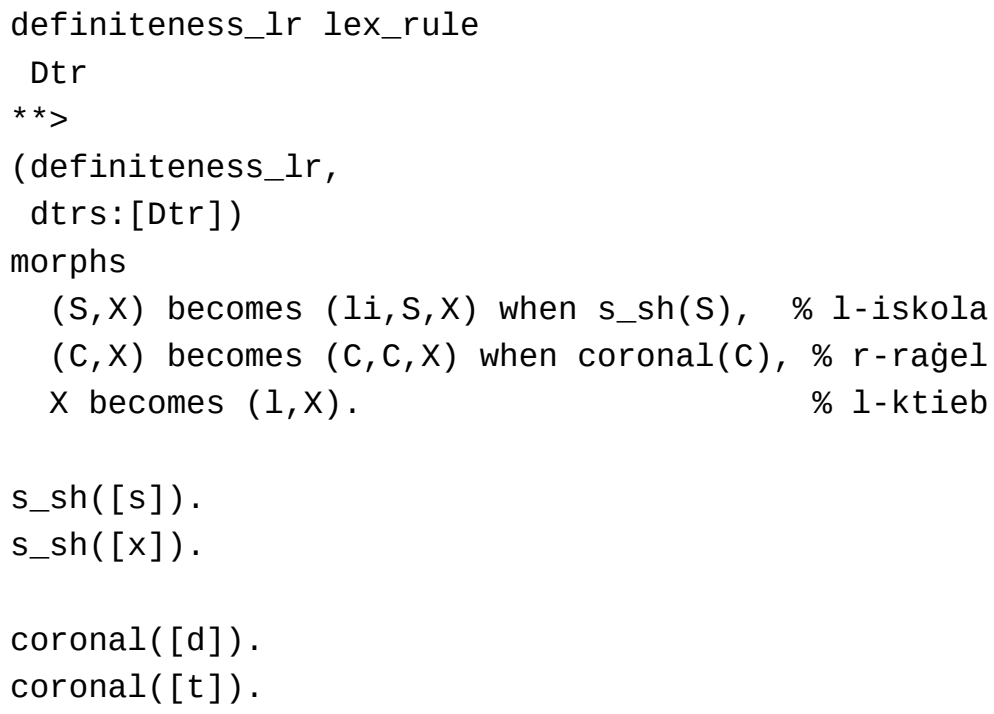

${ }^{20} \mathrm{~A}$ reviewer asked whether CoreGram parses sounds or orthographic representations. The latter is the case, but since the Maltese spelling is close to the phonological representation in the relevant area, phonological concepts like coronal can be used in the rules that relate orthographic forms. s_sh/1 and coronal/1 are Prolog predicates. 


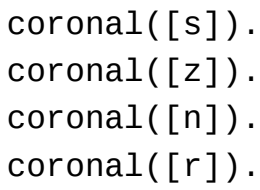

Setup of CoreGram

The grammars are organized in one directory for every language. The respective directories contain a subdirectory named Core-Grammar. This directory contains files that are shared between the grammars. For instance, the file core-macros.pl contains macros that are or can be used by all languages. For every language, there is a load file to fetch the relevant files from the core grammar directory that. So, for instance english.pl, french.pl, and danish.pl all load nom-acc.pl since these languages are nominative-accusative languages. These files also contain code for loading macros and constraints for languages that do not form a verbal complex, while german.pl does load the files for cluster-forming languages. These files directly correspond to the constraint sets that were discussed in Section 2.

The option to specify type constraints makes it possible to state constraints that hold for a certain construction cross-linguistically in a file that is loaded by all grammars and restrict structures of this type further in language-particular files.

Lexical rules are also described by feature descriptions and organized in type hierarchies (Meurers 2001). Just like other constraints, the constraints on lexical rules can be shared.

6

$$
\begin{aligned}
& \text { GOMPARISON TO OTHER } \\
& \text { MULTILINGUAL PROJEGTS }
\end{aligned}
$$

Two other large groups are currently working in the area of multilingual grammar engineering. We will deal with both of them in the following subsections and will explain in what way the CoreGram project differs from them. The DELPH-IN consortium ${ }^{21}$ will be described in Section 6.1, and ParGram in Section 6.2.

\footnotetext{
${ }^{21}$ DELPH-IN is an abbreviation for Deep Linguistic Processing with HPSG.
} 
The DELPH-IN group uses the LKB system (Copestake 2002) for grammar development. The LinGO Grammar Matrix provides a collection of types for lexical objects and phrasal schemata that can be used by grammar writers (Bender et al. 2002; Bender and Flickinger 2005). The Matrix builds on experiences from the development of grammars for English, German, Japanese, and Spanish. The Grammar Matrix provides a starter set. This can be modified and extended by individual grammar writers without any interaction with any other grammars that were derived from the Matrix. Of course, there is a feedback loop: Grammar writers can inform the developers of the Grammar Matrix about their requirements and changes which they believe to be appropriate. In the CoreGram project all grammars use the same core files. If the grammar core is changed because of evidence in, say, Persian, all other grammars have to be compatible with the change or have to be adapted. While this increases the complexity of the development process considerably, the result is a consistent set of grammars with partly shared constraints for several typologically diverse languages.

Work that is done in the DELPH-IN consortium has a strong focus on applications. Efficient processing has a high priority. This, among other causes, led to a reduction of the expressive power of the description formalism and is also reflected in analyses. See, for instance, (Crysmann 2003) and the criticism in (Müller 2005, Section 3.6). In our project, we see processing issues as secondary and want to treat computationally expensive, but linguistically interesting phenomena as well as those that can be handled efficiently. Although the development of linguistically motivated analyses has the highest priority, processability is not ignored completely. Since profiling tools (chart display and the test suite tool [incr tsdb()], see Oepen and Carroll 2000) are integrated into TRALE, an exact examination of the grammars is possible, and unnecessary computations of the parser can be detected and eliminated.

ParGram

A similar community to the DELPH-IN consortium is working in the framework of LFG and is organized in the ParGram project (Butt et al. 1999, 2002). The goal of the project is the implementation of parallel 
LFG grammars for a set of languages. Currently, there exist grammars for Arabic, Danish, English, Georgian, German, Hungarian, Japanese, Malagasy, Norwegian, Polish, Tigrinya, Turkish, Hungarian, Urdu, Vietnamese, Welsh, and Wolof (see Müller 2015b, Chapter 6, for an overview and references). These grammars are parallel in that they produce f-structures that have the same feature geometry and uniform analyses of the phenomena. Parallel grammar development is challenging for developers, since each phenomenon has to be examined carefully, and it has to be decided whether a cross-linguistic analysis is feasible at all, whether the phenomenon is idiosyncratic and language-specific, or whether the feature geometry has to be changed. The grammars are developed in the X(erox) L(inguistic) E(nvironment) system (Kaplan et al. 2002; Butt et al. 1999).

The ambitions of our project (and also the Grammar Matrix) are higher than those of the ParGram project, since HPSG grammars model the whole range of grammatical properties: Morphology, syntax, semantics, and information structure are described with the same feature geometry. Dominance schemata for head-argument phrases, head-adjunct phrases, filler-head phrases, specifier-head phrases, and so on are specified for all languages or for certain language classes. In comparison, computational LFG grammars differ enormously in their c-structures, while morphology is usually taken care of by external programs (Finite State Morphology) and is not part of theoretical considerations. Since, for instance, complex predicate formation in languages such as German and Persian interacts with derivational morphology (Müller 2003b, 2010b), we consider it crucial that morphology is dealt with within the grammatical framework, and that the computational implementation reflects the tight connection between the two parts of grammar.

7

\section{MEASURING PROGRESS}

Much to the frustration of many linguists, the contribution of certain theoretical approaches to progress in linguistics is rather unclear. Many proposals do not extend the amount of data that was already covered by analyses developed during the 1980s in the framework of GB and other, non-transformational, frameworks. In comparison, the methodology described in Section 2 leads to grammars with in- 
creasing coverage and analyses that are improved by cross-linguistic considerations.

The TRALE system has been combined with [incr tsdb()], a piece of software for systematic grammar profiling (Oepen and Flickinger 1998). The grammars are accompanied with a set of example phrases that can be analyzed by the grammar. In addition, the test suite files contain ungrammatical word sequences from the literature and ungrammatical sequences that were discovered during the grammar development process. See (Oepen et al. 1997; Müller 2004) on the construction of test suites. Since TRALE has a chart display that makes it possible to inspect the parse chart, it is possible to inspect all linguistic objects that are licensed by the grammar, even if they do not play a role in analyzing the particular sentence under consideration. The result of this careful inspection is a collection of ungrammatical word sequences that no theoretical linguist would have been able to come up with, since it is very difficult to find all the possible side effects of an analysis that is not sufficiently constrained. These negative examples are distributed with the grammars and book publications and can help theoretical and computational linguists improve their theories and implementations.

After changing a grammar, the sentences of the respective test suite are parsed and the result can be compared to previous results. This ensures that the coverage of grammars is extended. If constraints in files that are shared among several grammars are changed, the respective grammars are tested as well. The effects that changes to grammar $\mathrm{X}$ cause in grammar $\mathrm{Y}$ are often unexpected, and hence it is very important to do systematic testing.

I have discussed desiderata for linguistic theories and argued that linguistic theories have reached a level of complexity that cannot be handled by humans without help by computers. I have presented a certain type of UG-based approaches to natural language that assumes that evidence for an entity in a certain language provides evidence for the presence in other languages as well, even though the entity might be covert in the latter languages. I have argued that such lines of argumentation are not appropriate given what we 
know about language acquisition today. I have suggested an alternative bottom-up method for constructing theories by developing grammars that are surface-oriented and motivated on a languagespecific basis, without stipulating entities that could not be acquired from input of the language under consideration alone. Generalizations regarding language or language classes are derived by extending the number of languages that are considered and by organizing the constraints of the languages under consideration into sets of constraints that are shared by two or more languages. I have defended this method against rather agnostic views maintained by some typologists. Finally, I have provided a brief description of basic assumptions and the basic setup of the CoreGram project and argued that working in such a general setting makes sure that progress is made.

9

\section{AGKNOWLEDGEMENTS}

I thank Hans-Heinrich Lieb, Antonio Machicao y Priemer and three reviewers of the Journal of Language Modeling for comments on earlier versions of this paper; Werner Abraham, Peter Eisenberg, Evelina Fedorenko, Ted Gibson, Matthias Hüning, Tibor Kiss, Jean-Pierre Koenig, Elisabeth Leiss, Bob Levine, Frank Richter, Gerald Penn, Geoffrey Pullum, Uli Reich, Ivan Sag, Anatol Stefanowitsch and Dieter Wunderlich for discussion; and Philippa Cook and Adam Przepiórkowski for comments and proof-reading.

In 2013, parts of this paper were presented at the MIT Gibson Lab, Brain and Cognitive Sciences. I also presented this work in Alexander Koller's Theoretical Computational Linguistics group at the University of Potsdam in 2014, at the ESSLLI 2013 Workshop on High-level Methodologies for Grammar Engineering in Düsseldorf, which was organized by Denys Duchier and Yannick Parmentier, and at the workshop Grammatical categories in macro- and microcomparative linguistics, which was organized by Martin Haspelmath, Andreas Dufter, and Aria Adli at the annual meeting of the DGfS in Marburg in 2014. I thank the respective organizers for the invitations/inclusions into workshop programs, and all the participants for discussion.

The work reported in this paper was supported by grants from the Deutsche Forschungsgemeinschaft (InfStruk MU 2822/1-1, SFB 
632 project A6, DanGram MU 2822/2-1, PerGram MU 2822/3-1, and ChinGram MU 2822/5-1).

Last but not least, I want to thank the copy editors of the Journal of Language Modelling. They did a very good job on the manuscript!

\section{REFERENGES}

Steven P. ABNEY (1996), Statistical methods and linguistics, in Judith L. KLAVANS and Philip RESNIK, editors, The Balancing Act: Combining Symbolic and Statistical Approaches to Language, Language, Speech, and Communication, pp. 1-26, MIT Press.

Steven P. ABNEY and Jennifer COLE (1986), A government-binding parser, Proceedings of North Eastern Linguistic Society, 16:1-17.

Mansour ALOTAIBI and Robert D. BORSLEY (2013), Gaps and resumptive pronouns in Modern Standard Arabic, in Proceedings of the 20th International Conference on Head-Driven Phrase Structure Grammar, pp. 6-26, http:

//cslipublications. stanford.edu/HPSG/2013/alotaibi-borsley. pdf.

Ben AMBridge and Adele E. GoldBerg (2008), The island status of clausal complements: Evidence in favor of an information structure explanation, Cognitive Linguistics, 19:349-381, http ://www . princeton . edu/ adele/ Publications_files/08Ambridge\%26Goldberg-islands.pdf.

Joseph AOUN and Dominique SPORTICHE (1983), On the formal theory of government, The Linguistic Review, 2(3):211-236.

Mohammad BAhrani, Hossein SAmeti, and Mehdi Hafezi MANSHAdi (2011), A computational grammar for Persian based on GPSG, Language Resources and Evaluation, 45(4):387-408.

Colin Bannard, Elena Lieven, and Michael Tomasello (2009), Modeling children's early grammatical knowledge, Proceedings of the National Academy of Sciences, 106(41):17284-17289.

Emily BENDER and Daniel P. FLICKINGER (1999), Peripheral constructions and core phenomena: Agreement in tag questions, in Gert WEBELHUTH, Jean-Pierre KoENIG, and Andreas KATHOL, editors, Lexical and Constructional Aspects of Linguistic Explanation, number 1 in Studies in Constraint-Based Lexicalism, pp. 199-214, CSLI Publications.

Emily M. BENDER (2000), Syntactic Variation and Linguistic Competence: The Case of AAVE Copula Absence, Ph.D. thesis, Stanford University, http://faculty. washington . edu/ebender/dissertation/.

Emily M. BENDER (2008), Grammar engineering for linguistic hypothesis testing, in Proceedings of the Texas Linguistics Society $X$ Conference: Computational Linguistics for Less-Studied Languages, pp. 16-36. 
Emily M. BENDER and Daniel P. FLICKINGER (2005), Rapid prototyping of scalable grammars: Towards modularity in extensions to a language-independent core, in Proceedings of the 2nd International Joint Conference on Natural Language Processing IJCNLP-05 (Posters/Demos), http://turing.cs.washington. edu/papers/modules05.pdf.

Emily M. BENDER, Daniel P. Flickinger, and Stephan OEPEN (2002), The grammar matrix: An open-source starter-kit for the rapid development of cross-linguistically consistent broad-coverage precision grammars, in Proceedings of the Workshop on Grammar Engineering and Evaluation at COLING 2002, pp. 8-14.

Benjamin K. BERGEN and Nancy CHANG (2005), Embodied Construction Grammar in simulation-based language understanding, in Jan-Ola ÖsTMAN and Mirjam FRIED, editors, Construction Grammars: Cognitive Grounding and Theoretical Extensions, pp. 147-190, John Benjamins Publishing Co.

Robert C. Berwick, Paul Pietroski, Beracah YANKAMA, and Noam CHOMSKY (2011), Poverty of the stimulus revisited, Cognitive Science, 35(7):1207-1242.

Manfred BIERWISCH (1963), Grammatik des deutschen Verbs [The Grammar of the German Verb], number 2 in studia grammatica, Akademie Verlag.

Mahmood BIJANKHAN (2004), The role of corpora in writing a grammar [article in Persian], Iranian Journal of Linguistics, 19(2):48-67.

Felix BILDHAUER (2008), Representing Information Structure in an HPSG Grammar of Spanish, Ph.D. thesis, Universität Bremen.

Felix BILDHAUER and Philippa COOK (2010), German multiple fronting and expected topic-hood, in Proceedings of the 17th International Conference on Head-Driven Phrase Structure Grammar, pp. 68-79.

Rens BOD (2009), From exemplar to grammar: Integrating analogy and probability in language learning, Cognitive Science, 33(4):752-793, http://staff. science. uva.nl/ rens/analogy.pdf.

Olivier BONAMI and Danièle GODARD (2001), Inversion du sujet, constituance et ordre des mots, in Jean-Marie MARANDIN, editor, Cahier Jean-Claude Milner, pp. 117-174, Editions Verdier.

Olivier BONAMI, Daniele GODARD, and Jean-Marie MARANDIN (1998), French subject inversion in extraction contexts, Proceedings of FHCG, 98:101-112.

Robert D. BORSLEY (2004), An approach to English comparative correlatives, in Proceedings of the 11th International Conference on Head-Driven Phrase Structure Grammar, pp. 70-92.

Gosse Bouma, Robert MALOuf, and Ivan A. SAG (2001), Satisfying constraints on extraction and adjunction, Natural Language and Linguistic Theory, 19(1):1-65, http://ftp-linguistics . stanford. edu/sag/bms-nllt . pdf. 
Joan BRESNAN and Sam A. Мсномво (1995), The lexical integrity principle: Evidence from Bantu, Natural Language and Linguistic Theory, 13:181-254.

Ted J. BRISCOE and Ann COPESTAKE (1999), Lexical rules in constraint-based grammar, Computational Linguistics, 25(4):487-526, http://acl. ldc. upenn. edu/J/J99/J99-4002. pdf.

Miriam ButT, Helge Dyvik, Tracy Holloway KIng, Hiroshi Masuichi, and Christian ROHRER (2002), The parallel grammar project, in Proceedings of the Workshop on Grammar Engineering and Evaluation at COLING 2002, pp. 1-7.

Miriam ButT, Tracy Holloway KING, María-Eugenia NiÑo, and Frédérique SEGOND (1999), A Grammar Writer's Cookbook, number 95 in CSLI Lecture Notes, CSLI Publications.

Noam CHомsкy (1957), Syntactic Structures, number 4 in Janua Linguarum, Series Minor, Mouton.

Noam Сномsку (1959), On certain formal properties of grammars, Information and Control, 2(2):137-167.

Noam CHoMsky (1964), Degrees of grammaticalness, in Jerry A. FoDOR and Jerrold J. KATZ, editors, The Structure of Language, pp. 384-389, Prentice-Hall.

Noam Сномsку (1968), Language and the mind, Psychology Today, 1(9):48-68, Reprint as: Chomsky 1976.

Noam Сномкку (1971), Problems of Knowledge and Freedom, Fontana.

Noam Сномsку (1975), The Logical Structure of Linguistic Theory, Plenum Press.

Noam CHOMSKY (1976), Language and the mind, in Diane D. BorsteIN, editor, Readings in the Theory of Grammar: From the 17th to the 20th Century, pp. 241-251, Winthrop, Reprint from: Chomsky 1968.

Noam CHомsкy (1981), Lectures on Government and Binding, Foris Publications.

Noam Сномsку (1990), On formalization and formal linguistics, Natural Language and Linguistic Theory, 8(1):143-147.

Noam Сномsкy (1995), The Minimalist Program, number 28 in Current Studies in Linguistics, MIT Press.

Noam Chомsкy (2001), Derivation by phase, in Michael Kenstowicz, editor, Ken Hale. A Life in Language, pp. 1-52, MIT Press.

Noam CHOMSKY (2007), Approaching UG from below, in Uli SAUERLAND and Hans-Martin GÄRTNER, editors, Interfaces + Recursion = Language? Chomsky's Minimalism and the View from Syntax-Semantics, number 89 in Studies in Generative Grammar, pp. 1-29, Mouton de Gruyter.

Noam CHомsкy (2008), On phases, in Robert Freidin, Carlos P. OTERo, and Maria Luisa ZubIZARRETA, editors, Foundational Issues in Linguistic Theory. Essays in Honor of Jean-Roger Vergnaud, pp. 133-166, MIT Press. 
Noam Сномsкy (2013), Problems of projection, Lingua, 130:33-49.

Guglielmo CINQUE (1999), Adverbs and Functional Heads. A Cross-Linguistic Perspective, Oxford University Press.

Guglielmo CINQUE and Luigi RIzzI (2010), The cartography of syntactic structures, in Bernd HEINE and Heiko NARROG, editors, The Oxford Handbook of Linguistic Analysis, pp. 51-65, Oxford University Press.

Charles Jr. CLIFTON and Penelope OdOM (1966), Similarity relations among certain English sentence constructions, Psychological Monographs: General and Applied, 80(5):1-35.

Ann COPESTAKE (2002), Implementing Typed Feature Structure Grammars, number 110 in CSLI Lecture Notes, CSLI Publications.

Ann Copestake, Daniel P. Flickinger, Carl J. Pollard, and Ivan A. SAG (2005), Minimal Recursion Semantics: An introduction, Research on Language and Computation, 4(3):281-332,

http://lingo.stanford.edu/sag/papers/copestake. pdf.

Nelson CORREA (1987), An attribute-grammar implementation of Government-Binding Theory, in Proceedings of the 25th Annual Meeting of the Association for Computational Linguistics, pp. 45-51, http: //acl . ldc . upenn . edu/P/P87/P87-1007. pdf.

Matthew Walter CROCKER and Ian LEWIN (1992), Parsing as deduction: Rules versus principles, in Proceedings of the loth European Conference on Artificial Intelligence, pp. 508-512.

William CROFT (2001), Radical Construction Grammar: Syntactic Theory in Typological Perspective, Oxford University Press.

Berthold CRYSMANN (2003), On the efficient implementation of German verb placement in HPSG, in Proceedings of RANLP 2003, pp. 112-116.

Peter W. Culicover (1999), Syntactic Nuts: Hard Cases, Syntactic Theory, and Language Acquisition, volume 1 of Foundations of Syntax, Oxford University Press.

Peter W. Culicover and Ray S. JACKendoff (2005), Simpler Syntax, Oxford University Press.

Kordula DE KuTHY (2002), Discontinuous NPs in German, number 14 in Studies in Constraint-Based Lexicalism, CSLI Publications.

Johannes Dellert, Kilian EvANG, and Frank RICHTER (2010), Kahina, a debugging framework for logic programs and TRALE, presentation at the 17th International Conference on Head-Driven Phrase Structure Grammar.

Johannes Dellert, Kilian EVANG, and Frank Richter (2013), Kahina: A hybrid trace-based and chart-based debugging system for grammar engineering, in Proceedings of the Workshop on High-level Methodologies for Grammar Engineering (HMGE 2013), pp. 75-86. 
David R. DowTy (1979), Word Meaning and Montague Grammar, number 7 in Synthese Language Library, D. Reidel Publishing Company.

David R. DowTY (1991), Thematic proto-roles and argument selection, Language, 67(3):547-619.

Matthew S. DRYER (1997), Are grammatical relations universal?, in Joan BYBEE, John HAIMAN, and Sandra THOMPSON, editors, Essays on Language Function and Language Type: Dedicated to T. Givon, pp. 115-143, John Benjamins Publishing Co.

Markus EGG (1999), Derivation and resolution of ambiguities in wieder-sentences, in Proceedings of the 12th Amsterdam Colloquium, pp. 109-114.

Peter EISENBERg (1992), Platos Problem und die Lernbarkeit der Syntax [Plato's problem and the learnability of syntax], in Peter SUCHSLAND, editor, Biologische und soziale Grundlagen der Sprache, number 280 in Linguistische Arbeiten, pp. 371-378, Max Niemeyer Verlag.

Elisabet ENGDAHL and Enric VALLDUVí (1994), Information packaging and grammar architecture: A constraint-based approach, in Elisabet ENGDAHL, editor, Integrating Information Structure into Constraint-Based and Categorial Approaches, pp. 39-79, ILLC, DYANA-2 Report R.1.3.B.

Elisabet ENGDAHL and Enric VALLDUVí (1996), Information packaging in HPSG, in Claire GROVER and Enric VALLDUví, editors, Edinburgh Working Papers in Cognitive Science, Vol. 12: Studies in HPSG, chapter 1, pp. 1-32, Centre for Cognitive Science, University of Edinburgh, ftp://ftp.cogsci.ed.ac.uk/pub/ccs-WPs/wp-12.ps.gz.

Bruno ESTIGARRIBIA (2009), Facilitation by variation: Right-to-left learning of English yes/no questions, Cognitive Science, 34(1):68-93.

Nicholas EvANS and Stephen C. LEVINSON (2009), The myth of language universals: Language diversity and its importance for cognitive science, The Behavioral and Brain Sciences, 32(5):429-448.

Arnold Evers (1975), The Transformational Cycle in Dutch and German, Ph.D. thesis, University of Utrecht.

Ray FABRI (1993), Kongruenz und die Grammatik des Maltesischen [Agreement and the Grammar of Maltese], number 292 in Linguistische Arbeiten, Max Niemeyer Verlag.

Gisbert FANSELOW (2001), Features, $\theta$-roles, and free constituent order, Linguistic Inquiry, 32(3):405-437.

Gisbert FANSELOW (2009), Die (generative) Syntax in den Zeiten der Empiriediskussion [(Generative) syntax in the times of the empirical evidence discussion], Zeitschrift für Sprachwissenschaft, 28(1):133-139.

Janet Dean FODOR (1998), Unambiguous triggers, Linguistic Inquiry, 29(1):1-36. 
Janet Dean FODOR (2001), Parameters and the periphery: Reflections on syntactic nuts, Journal of Linguistics, 37:367-392.

Jerry A. Fodor, Thomas G. BEVER, and Merrill F. GARRETT (1974), The Psychology of Language: An Introduction to Psycholinguistics and Generative Grammar, McGraw-Hill Book Co.

Sandiway FONG (1991), Computational Properties of Principle-Based Grammatical Theories, Ph.D. thesis, MIT Artificial Intelligence Lab, http://Www. neci.nec.com/homepages/sandiway/pappi/index.html.

Sandiway FONG (2014), Unification and efficient computation in the Minimalist Program, in L. FRANCIS and L. LAURENT, editors, Language and Recursion, pp. 129-138, Springer Verlag.

Sandiway FONG and Jason GINSBURG (2012), Computation with doubling constituents: Pronouns and antecedents in phase theory, in Anna Maria Di SCIULlO, editor, Towards a Biolinguistic Understanding of Grammar: Essays on Interfaces, number 194 in Linguistik Aktuell/Linguistics Today, pp. 303-338, John Benjamins Publishing Co.

Andrew FORDHAM and Matthew Walter CROCKER (1994), Parsing with principles and probabilities, in Proceedings of the Workshop "The Balancing Act: Combining Symbolic and Statistical Approaches to Language”, pp. 37-42.

Robert FREIDIN (1997), Review article: The Minimalist Program, Language, 73(3):571-582.

Daniel Freudenthal, Julian M. Pine, and Fernand Gobet (2006), Modeling the development of children's use of optional infinitives in Dutch and English using MOSAIC, Cognitive Science, 30(2):277-310.

Daniel Freudenthal, Julian M. Pine, and Fernand Gobet (2009), Simulating the referential properties of Dutch, German, and English root infinitives in MOSAIC, Language Learning and Development, 5(1):1-29.

Joyce FRIEDMAN (1969), Applications of a computer system for Transformational Grammar, in Proceedings of the International Conference on Computational Linguistics 1969.

Joyce Friedman, Thomas H. BREDT, Robert W. DORAN, Bary W. POLLACK, and Theodore S. MARTNER (1971), A Computer Model of Transformational Grammar, number 9 in Mathematical Linguistics and Automatic Language Processing, Elsevier.

Gerald GAZDAR, Ewan Klein, Geoffrey K. Pullum, and Ivan A. SAg (1985), Generalized Phrase Structure Grammar, Harvard University Press.

Edward GIBSON (1998), Linguistic complexity: Locality of syntactic dependencies, Cognition, 68(1):1-76. 
Jonathan GINZBURG and Ivan A. SAG (2000), Interrogative Investigations: the Form, Meaning, and Use of English Interrogatives, number 123 in CSLI Lecture Notes, CSLI Publications.

Mark E. GoLD (1967), Language identification in the limit, Information and Control, 10(5):447-474.

Adele E. GoldBerg (2013), Argument structure constructions vs. lexical rules or derivational verb templates, Mind and Language, 28(4):435-465.

Günther GREWENDORF (1988), Aspekte der deutschen Syntax. Eine Rektions-Bindungs-Analyse [Aspcets of German Syntax. A Govenment and Binding Analysis], number 33 in Studien zur deutschen Grammatik, originally Gunter Narr Verlag now Stauffenburg Verlag.

Takao GuNJI (1986), Subcategorization and word order, in William J. POsER, editor, Papers from the Second International Workshop on Japanese Syntax, pp. 1-21, CSLI Publications.

Hubert HAIDER (1986), Fehlende Argumente: vom Passiv zu kohärenten Infinitiven [Missing arguments: from passive to coherent infinitives], Linguistische Berichte, 101:3-33.

Daniel HARBour (2011), Mythomania? methods and morals from 'the myth of language universals', Lingua, 121(12):1820-1830.

Martin HASPELMATH (2010a), Comparative concepts and descriptive categories in crosslinguistic studies, Language, 86(3):663-687.

Martin HASPELMATH (2010b), The interplay between comparative concepts and descriptive categories (reply to Newmeyer), Language, 86(3):696-699.

Petter Haugereid, Nurit Melnik, and Shuly Wintner (2013), Nonverbal predicates in Modern Hebrew, in Proceedings of the 20th International Conference on Head-Driven Phrase Structure Grammar, pp. 69-89, http://cslipublications. stanford. edu/HPSG/2013/hmw. pdf.

Marc D. HAuser, Noam CHOMsKy, and W. Tecumseh Fitch (2002), The faculty of language: What is it, who has it, and how did it evolve?, Science, 298:1569-1579, doi:10.1126/science.298.5598.1569, http: //WWW. chomsky . info/articles/20021122. pdf.

Wolfgang HEINZ and Johannes MATIASEK (1994), Argument structure and case assignment in German, in John NERBONNE, Klaus NETTER, and Carl J. POLLARD, editors, German in Head-Driven Phrase Structure Grammar, number 46 in CSLI Lecture Notes, pp. 199-236, CSLI Publications.

Erhard W. HINRICHS and Tsuneko NAKAZAWA (1994), Linearizing AUXs in German verbal complexes, in John NERBOnNe, Klaus NETTER, and Carl J. POLLARD, editors, German in Head-Driven Phrase Structure Grammar, number 46 in CSLI Lecture Notes, pp. 11-38, CSLI Publications. 
Anders Holmberg (1999), Remarks on Holmberg's generalization, Studia Linguistica, 53(1):1-39.

Norbert HORNSTEIN, Jairo NUNES, and Kleantes K. GROHMANN (2005), Understanding Minimalism, Cambridge Textbooks in Linguistics, Cambridge University Press.

Ray S. JACKENDOFF (1997), The Architecture of the Language Faculty, number 28 in Linguistic Inquiry Monographs, MIT Press.

Ray S. JACKENDOFF (1999), Parallel constraint-based generative theories of language, Trends in Cognitive Science, 3(10):393-400.

Ray S. JACKENDOFF (2008), Construction after construction and its theoretical challenges, Language, 84(1):8-28.

Ray S. JACKENDOFF (2011), What is the human language faculty? Two views, Language, 87(3):586-624.

Ray S. JACKENDOFF and Steven PINKER (2005), The nature of the language faculty and its implications for evolution of language (reply to Fitch, Hauser, and Chomsky), Cognition, 97(2):211-225.

Joachim JACOBS (2008), Wozu Konstruktionen? [Why constructions?], Linguistische Berichte, 213:3-44.

Gerhard JÄGER and Reinhard BLUTNER (2003), Competition and interpretation: The German adverb wieder ("again"), in Ewald LANG, Claudia MAIEnBorn, and Cathrine FABricius-HANSEN, editors, Modifying Adjuncts, number 4 in Interface Explorations, pp. 393-416, Mouton de Gruyter.

Kent JoHnson (2004), Gold's theorem and cognitive science, Philosophy of Science, 71(4):571-592.

Ronald M. KAPlAN, Tracy Holloway KING, and John T. MAXWELL III (2002), Adapting existing grammars: The XLE approach, in Proceedings of the Workshop on Grammar Engineering and Evaluation at COLING 2002, pp. 29-35, ht tp:

//www2 . parc. com/isl/groups/nltt/pargram/kaplanetal-colinge2. pdf.

Gholamhossein KARIMI-Doostan (1997), Light Verb Constructions in Persian, Ph.D. thesis, Department of Language and Linguistics, University of Essex.

Martin KAY (2011), Zipf's law and L'Arbitraire du Signe, Linguistic Issues in Language Technology, 6(8): Special Issue on Interaction of Linguistics and Computational Linguistics,

http://elanguage.net/journals/index.php/lilt/issue/view/330.

Richard S. KAYNE (1994), The Antisymmetry of Syntax, number 25 in Linguistic Inquiry Monographs, MIT Press.

Edward L. KEENAN and Bernard COMRIE (1977), Noun phrase accessibility and universal grammar, Linguistic Inquiry, 8(1):63-99. 
Tibor KIss (1995), Infinite Komplementation. Neue Studien zum deutschen Verbum infinitum [Non-finite Complementation. New Studies on the German Non-Finite Verb], number 333 in Linguistische Arbeiten, Max Niemeyer Verlag.

Jean-Pierre KoENIG and Anthony R. DAVIS (2004), Raising doubts about Russian impersonals, in Proceedings of the 11th International Conference on Head-Driven Phrase Structure Grammar.

Jean-Pierre KoEnIG and Karin Michelson (2012), The (non)universality of syntactic selection and functional application, in Empirical Issues in Syntax and Semantics, volume 9, pp. 185-205.

Hans-Peter KOLB (1997), GB blues: Two essays on procedures and structures in generative syntax, Arbeitspapiere des SFB 340 No. 110,

Eberhard-Karls-Universität, Tübingen.

Hans-Peter KolB and Craig L. THIERsCH (1991), Levels and empty categories in a Principles and Parameters based approach to parsing, in Hubert HAIDER and Klaus NETTER, editors, Representation and Derivation in the Theory of Grammar, number 22 in Studies in Natural Language and Linguistic Theory, Kluwer Academic Publishers.

Alexander KolLER and Stefan THATER (2005), Efficient solving and exploration of scope ambiguities, in Proceedings of the ACL Interactive Poster and Demonstration Sessions, pp. 9-12, http://acl. ldc. upenn. edu/P/P05/P05-3003. pdf.

Ekkehard KÖNIG and Claire MOYSE-FAURIE (2009), Spatial reciprocity: Between grammar and lexis, in Johannes HELMBRECHT, Yoko NiSHINA, Yong-Min Shin, Stavros SKopeteAs, and Elisabeth Verhoeven, editors, Form and Function in Language Research: Papers in Honour of Christian Lehmann, number 210 in Trends in Linguistics. Studies and Monographs, pp. 57-68, de Gruyter.

András KornAI and Geoffrey K. Pullum (1990), The X-bar Theory of phrase structure, Language, 66(1):24-50.

Jonas KUHN (2007), Interfaces in constraint-based theories of grammar, in Gillian RAMCHAND and Charles REIss, editors, The Oxford Handbook of Linguistic Interfaces, pp. 613-650, Oxford University Press.

Robert J. KUHNS (1986), A PROLOG implementation of Government-Binding Theory, in Proceedings of the 24th Annual Meeting of the Association for Computational Linguistics, pp. 546-550.

Marie LABELLE (2007), Biolinguistics, the Minimalist Program, and psycholinguistic reality, Snippets, 14, http://Www. ledonline.it/snippets/.

Shalom LAPPIn, Robert D. LEVInE, and David E. JoHnson (2000), The revolution confused: A response to our critics, Natural Language and Linguistic Theory, 18(4):873-890. 
Robert D. LEVINE and Thomas E. HUKARI (2006), The Unity of Unbounded Dependency Constructions, number 166 in CSLI Lecture Notes, CSLI Publications.

Charles N. LI and Sandra A. THOMPson (1981), Mandarin Chinese. A Functional Reference Grammar, University of California Press.

Janna LIPENKOVA (2009), Serienverbkonstruktionen im Chinesischen und ihre Analyse im Rahmen von HPSG [Serial Verb Constructions in Chinese and their Analysis in the Framework of HPSG], Master's thesis, Institut für Sinologie, Freie Universität Berlin, http://hpsg . fu-berlin.de/ lipenkov/magister . html.

Horst LOHNSTEIN (1993), Projektion und Linking. Ein prinzipienbasierter Parser fürs Deutsche [Projection and Linking. A Principle-Based Parser for German], number 287 in Linguistische Arbeiten, Max Niemeyer Verlag.

Alec MARANTZ (2005), Generative linguistics within the cognitive neuroscience of language, The Linguistic Review, 22(2-4):429-445.

Mitchell P. MARCUS (1980), A Theory of Syntactic Recognition for Natural Language, MIT Press.

William MARSLEN-WILSON (1975), Sentence perception as an interactive parallel process, Science, 189(4198):226-228.

Nurit MELNIK (2007), From "hand-written" to computationally implemented HPSG theories, Research on Language and Computation, 5(2):199-236.

Walt D. Meurers, Kordula De Kuthy, and Vanessa Metcalf (2003), Modularity of grammatical constraints in HPSG-based grammar implementations, in Proceedings of the ESSLLI 2003 Workshop "Ideas and Strategies for Multilingual Grammar Development", pp. 83-90, ht tp : //www. sfs . uni-tuebingen. de/ dm/papers/meurers-dekuthy-metcalf- 03 . html.

Walt Detmar MEURERs (1999a), German partial-VP fronting revisited, in Gert Webelhuth, Jean-Pierre Koenig, and Andreas KATHOL, editors, Lexical and Constructional Aspects of Linguistic Explanation, number 1 in Studies in Constraint-Based Lexicalism, pp. 129-144, CSLI Publications, http://www.sfs.uni-tuebingen.de/ dm/papers/hpsg-volume98/ pvp-revisited.html.

Walt Detmar MEURERs (1999b), Lexical Generalizations in the Syntax of German Non-Finite Constructions, Ph.D. thesis, Eberhard-Karls-Universität, Tübingen.

Walt Detmar MEURERs (1999c), Raising spirits (and assigning them case), Groninger Arbeiten zur Germanistischen Linguistik (GAGL), 43:173-226, http://wWw.sfs. uni-tuebingen. de/ dm/papers/gagl99.html.

Walt Detmar MEuRERs (2000), Lexical generalizations in the syntax of German non-finite constructions, Arbeitspapiere des SFB 340 No. 145, Eberhard-Karls-Universität, Tübingen, http://wWw.sfs. uni-tuebingen.de/ dm/papers/diss.html. 
Walt Detmar MEURERS (2001), On expressing lexical generalizations in HPSG, Nordic Journal of Linguistics, 24(2):161-217, http : //Www. sfs .

uni-tuebingen.de/ dm/papers/lexical-generalizations . html.

Walt Detmar Meurers, Gerald PenN, and Frank Richter (2002), A web-based instructional platform for constraint-based grammar formalisms and parsing, in Effective Tools and Methodologies for Teaching NLP and CL, pp. 18-25, http://www.sfs. uni-tuebingen.de/ dm/papers/aclo2.html, proceedings of the Workshop held at 40th Annual Meeting of the Association for Computational Linguistics. Philadelphia, PA.

George A. MiLleR and Kathryn Ojemann McKeAN (1964), A chronometric study of some relations between sentences, Quarterly Journal of Experimental Psychology, 16(4):297-308.

Yves Ch. Morin (1973), A computer tested Transformational Grammar of French, Linguistics, 116(11):49-114.

Gereon MüLLER (1998), Incomplete Category Fronting. A Derivational Approach to Remnant Movement in German, number 42 in Studies in Natural Language and Linguistic Theory, Kluwer Academic Publishers.

Gereon MüLLER (2011), Regeln oder Konstruktionen? Von verblosen Direktiven zur sequentiellen Nominalreduplikation [Rules or constructions? From verbless directives to sequential nominal reduplication], in Stefan ENGELBERG, Anke HOLLER, and Kristel ProOst, editors, Sprachliches Wissen zwischen Lexikon und Grammatik, Institut für Deutsche Sprache, Jahrbuch 2010, pp. 211-249, de Gruyter, http://www. uni-leipzig.de/ muellerg/mu242.pdf.

Stefan Müller (1999), Deutsche Syntax deklarativ. Head-Driven Phrase Structure Grammar für das Deutsche [German Syntax Declarative. Head-Driven Phrase Structure Grammar for German], number 394 in Linguistische Arbeiten, Max Niemeyer Verlag, http://hpsg.fu-berlin.de/ stefan/Pub/hpsg.html.

Stefan MüLLER (2002), Complex Predicates: Verbal Complexes, Resultative Constructions, and Particle Verbs in German, number 13 in Studies in Constraint-Based Lexicalism, CSLI Publications, http://hpsg.fu-berlin.de/ stefan/Pub/complex.html.

Stefan MüLLER (2003a), Mehrfache Vorfeldbesetzung [Multiple frontings], Deutsche Sprache, 31(1):29-62, http://hpsg.fu-berlin.de/ stefan/Pub/mehr-vf-ds.html.

Stefan MüLLER (2003b), Solving the bracketing paradox: an analysis of the morphology of German particle verbs, Journal of Linguistics, 39(2):275-325, http://hpsg.fu-berlin.de/ stefan/Pub/paradox.html.

Stefan MüLLER (2004), Example sentences and making them useful for theoretical and computational linguistics, Presentation at the DGfS Jahrestagung: AG Empirische Fundierung der Modellbildung in der Syntax, 
http:

//hpsg.fu-berlin.de/ stefan/PS/b-ger-ts-dgfs-2004-slides.pdf.

Stefan MüLLER (2005), Zur Analyse der deutschen Satzstruktur [Towards the analysis of the German sentence structure], Linguistische Berichte, 201:3-39, http://hpsg.fu-berlin.de/ stefan/Pub/satz-lb.html.

Stefan MüLLER (2006), Phrasal or lexical constructions?, Language, 82(4):850-883, http://hpsg.fu-berlin.de/ stefan/Pub/phrasal. html.

Stefan MülLER (2007a), The Grammix CD Rom: A software collection for developing typed feature structure grammars, in Tracy Holloway KING and Emily M. BENDER, editors, Grammar Engineering across Frameworks 2007, Studies in Computational Linguistics ONLINE, CSLI Publications.

Stefan MÜLlER (2007b), Head-Driven Phrase Structure Grammar: Eine Einführung, number 17 in Stauffenburg Einführungen, Stauffenburg Verlag, 1st edition, http://hpsg.fu-berlin.de/ stefan/Pub/hpsg-lehrbuch.html.

Stefan MÜLLER (2008), Depictive secondary predicates in German and English, in Christoph Schroeder, Gerd Hentschel, and Winfried BoEdER, editors, Secondary Predicates in Eastern European Languages and Beyond, number 16 in Studia Slavica Oldenburgensia, pp. 255-273, BIS-Verlag, http://hpsg.fu-berlin.de/ stefan/Pub/depiktiv-2006.html.

Stefan MÜllER (2009a), A Head-Driven Phrase Structure Grammar for Maltese, in Bernard Comrie, Ray FABRI, Beth Hume, Manwel Mifsud, Thomas Stolz, and Martine VANHOVE, editors, Introducing Maltese Linguistics: Papers from the 1st International Conference on Maltese Linguistics, number 113 in Studies in Language Companion Series, pp. 83-112, John Benjamins Publishing Co., http://hpsg.fu-berlin.de/ stefan/Pub/maltese-sketch.html.

Stefan MüLLER (2009b), On predication, in Proceedings of the 16th International Conference on Head-Driven Phrase Structure Grammar, pp. 213-233, http://hpsg.fu-berlin.de/ stefan/Pub/predication.html.

Stefan MüLLER (2010a), Grammatiktheorie [Grammatical Theory], number 20 in Stauffenburg Einführungen, Stauffenburg Verlag, http://hpsg.fu-berlin.de/ stefan/Pub/grammatiktheorie.html.

Stefan MÜLLER (2010b), Persian complex predicates and the limits of inheritance-based analyses, Journal of Linguistics, 46(3):601-655, http://hpsg.fu-berlin.de/ stefan/Pub/persian-cp.html.

Stefan MÜLLER (2012), On the copula, specificational constructions and type shifting, http://hpsg.fu-berlin.de/ stefan/Pub/copula.html, draft, Freie Universität Berlin.

Stefan MüLLER (2013a), Grammatiktheorie [Grammatical Theory], number 20 in Stauffenburg Einführungen, Stauffenburg Verlag, 2nd edition, http://hpsg.fu-berlin.de/ stefan/Pub/grammatiktheorie.html. 
Stefan MÜLLER (2013b), Head-Driven Phrase Structure Grammar: Eine Einführung [Head-Driven Phrase Structure Grammar: an Introduction], number 17 in Stauffenburg Einführungen, Stauffenburg Verlag, 3rd edition, http://hpsg.fu-berlin.de/ stefan/Pub/hpsg-lehrbuch.html.

Stefan MüLLER (2013c), Unifying everything: Some remarks on Simpler Syntax, Construction Grammar, Minimalism and HPSG, Language, 89(4):920-950, http://hpsg.fu-berlin.de/ stefan/Pub/unifying-everything .html.

Stefan MüLLER (2014a), Artenvielfalt und Head-Driven Phrase Structure Grammar [Biological diversity and Head-Driven Phrase Structure Grammar], in Syntaxtheorien: Analysen im Vergleich, number 28 in Stauffenburg Einführungen, pp. 187-233, Stauffenburg Verlag,

http://hpsg.fu-berlin.de/ stefan/Pub/artenvielfalt.html.

Stefan MüLLER (2014b), Elliptical constructions, multiple frontings, and surface-based syntax, in Proceedings of Formal Grammar 2004, pp. 91-109, http://hpsg.fu-berlin.de/ stefan/Pub/surface.html.

Stefan MüLLER (2014c), Kernigkeit: Anmerkungen zur

Kern-Peripherie-Unterscheidung [Coriness: Some remarks on the core-periphery distinction], in Andreas NOLDA, Athina SiOUPI, and

Antonio Machicao Y PRIEMER, editors, Zwischen Kern und Peripherie, number 76 in studia grammatica, pp. 25-39, de Gruyter, http://hpsg.fu-berlin.de/ stefan/Pub/kernigkeit.html.

Stefan MÜLLER (2014d), Satztypen: Lexikalisch oder/und phrasal [Sentence types. Lexically and/or phrasally], in Rita FinKBEINER and Jörg MEIBAUER, editors, Satztypen und Konstruktionen im Deutschen, Linguistik - Impulse und Tendenzen, de Gruyter, To appear.

Stefan MüLLER (2015a), German Sentence Structure: An Analysis with Special Consideration of So-Called Multiple Fronting, Empirically Oriented Theoretical Morphology and Syntax, Language Science Press, http://hpsg.fu-berlin.de/ stefan/Pub/gs.html, in Preparation.

Stefan MÜLLER (2015b), Grammatical Theory: From Transformational Grammar to Constraint-Based Approaches, number 1 in Lecture Notes in Language Sciences, Language Science Press, In Preparation.

Stefan MÜLlER (2015c), HPSG - a synopsis, in Artemis AlEXIADOU and Tibor KIss, editors, Syntax - Theory and Analysis. An International Handbook, number 42.2 in Handbooks of Linguistics and Communication Science, chapter 27, Walter de Gruyter, 2nd edition, http://hpsg.fu-berlin.de/ stefan/Pub/hpsg-hsk.html, In Print.

Stefan MÜlleR, Felix BILDHAUER, and Philippa COOK (2012), Beschränkungen für die scheinbar mehrfache Vorfeldbesetzung im Deutschen [Constraints on apparent multiple frontings in German], in Colette CoRTÈs, editor, 
Satzeröffnung. Formen, Funktionen, Strategien, number 31 in Eurogermanistik, pp. 113-128, Stauffenburg Verlag.

Stefan MÜLlER and Masood GHAyoomi (2010), PerGram: A TRALE implementation of an HPSG fragment of Persian, in Proceedings of the 2010 IEEE International Multiconference on Computer Science and Information Technology Computational Linguistics Applications (CLA'10), volume 5, pp. 461-467, http://hpsg.fu-berlin.de/ stefan/Pub/pergram.html.

Stefan MÜLLER and Janna LIPENKOVA (2009), Serial verb constructions in Chinese: An HPSG account, in Proceedings of the 16th International Conference on Head-Driven Phrase Structure Grammar, pp. 234-254, http://hpsg.fu-berlin.de/ stefan/Pub/chinese-svc.html.

Stefan MüLLER and Janna LIPENKOvA (2013), ChinGram: A TRALE implementation of an HPSG fragment of Mandarin Chinese, in Proceedings of the 27th Pacific Asia Conference on Language, Information, and Computation (PACLIC 27), pp. 240-249, Department of English, National Chengchi University.

Stefan MüLlER and Janna LiPEnKova (In Preparation), Mandarin Chinese in Head-Driven Phrase Structure Grammar, Empirically Oriented Theoretical Morphology and Syntax, Language Science Press.

Stefan MÜLLER and Bjarne ØRSNES (2011), Positional expletives in Danish, German, and Yiddish, in Proceedings of the 18th International Conference on Head-Driven Phrase Structure Grammar, pp. 167-187, http://hpsg.fu-berlin.de/ stefan/Pub/expletives.html.

Stefan MüLLER and Bjarne ØRSNES (2013a), Passive in Danish, English, and German, in Proceedings of the 20th International Conference on Head-Driven Phrase Structure Grammar, pp. 140-160.

Stefan MÜLLER and Bjarne ØRSNES (2013b), Towards an HPSG analysis of object shift in Danish, in Glyn MORRILL and Mark-Jan NEDERHOF, editors, Formal Grammar: 17th and 18th International Conferences, FG 2012/2013, number 8036 in Lecture Notes in Computer Science, pp. 69-89, Springer Verlag, http://hpsg.fu-berlin.de/ stefan/Pub/object-shift.html.

Stefan MÜLLER and Bjarne ØRSNES (2015), Danish in Head-Driven Phrase Structure Grammar, Empirically Oriented Theoretical Morphology and Syntax, Language Science Press, http://hpsg.fu-berlin.de/ stefan/Pub/danish.html, In Preparation.

Stefan Müller, Pollet SAmvelian, and Olivier Bonami (In Preparation), Persian in Head-Driven Phrase Structure Grammar, Empirically Oriented Theoretical Morphology and Syntax, Language Science Press, http://hpsg.fu-berlin.de/ stefan/Pub/persian.html.

Stefan MüLLER and Stephen Mark WECHSLER (2014), Lexical approaches to argument structure, Theoretical Linguistics, 40(1-2):1-76, http://hpsg.fu-berlin.de/ stefan/Pub/arg-st.html. 
Mariacristina Musso, Andrea Moro, Volkmar Glauche, Michel RiJntJes, Jürgen REICHENBACH, Christian BüCHEL, and Cornelius WEILlER (2003), Broca's area and the language instinct, Nature Neuroscience, 6(7):774-781. Klaus NETTER (1991), Clause union phenomena and complex predicates in German, in Klaus NETTER and Mike REAPE, editors, Clause Structure and Word Order Variation in Germanic, DYANA Report R1.1.B, University of Edinburgh.

Frederick J. NEWMEYER (2005), Possible and Probable Languages: A Generative Perspective on Linguistic Typology, Oxford University Press.

Frederick J. NEWMEYER (2010), On comparative concepts and descriptive categories: A reply to Haspelmath, Language, 86(3):688-695.

Sourabh NiYOGI and Robert C. BERWICK (2005), A Minimalist implementation of Hale-Keyser incorporation theory, in Anna Maria Di ScIULLO, editor, UG and External Systems: Language, Brain and Computation, number 75 in Linguistik Aktuell/Linguistics Today, pp. 269-288, John Benjamins Publishing Co.

Torbjørn NORDGÅRD (1994), E-Parser: An implementation of a deterministic GB-related parsing system, Computers and the Humanities, 28(4-5):259-272.

Geoffrey NunBERG, Ivan A. SAG, and Thomas WASOW (1994), Idioms, Language, 70(3):491-538.

Stephan OEPEN and John A. CARroll (2000), Parser engineering and performance profiling, Natural Language Engineering, 6(1):81-97, http://www. delph-in. net/itsdb/publications/parsing.ps.gz.

Stephan OEPEN and Daniel P. FLICKINGER (1998), Towards systematic grammar profiling. Test suite technology ten years after, Journal of Computer Speech and Language, 12(4):411-436, http://www.delph-in.net/itsdb/publications/profiling.ps.gz, (Special Issue on Evaluation).

Stephan OEPEN, Klaus NetTER, and Judith KLEIN (1997), TSNLP - Test Suites for Natural Language Processing, in John NERBONNE, editor, Linguistic Databases, pp. 13-36, CSLI Publications.

Bjarne ØRSNEs (2009), Preposed negation in Danish, in Proceedings of the 16th International Conference on Head-Driven Phrase Structure Grammar, pp. 255-275.

Gerald PENN (2004), Balancing clarity and efficiency in typed feature logic through delaying, in Proceedings of the 42nd Meeting of the Association for Computational Linguistics, pp. 239-246.

David M. PERLMUtTER (1978), Impersonal passives and the Unaccusative Hypothesis, in Proceedings of the 4th Annual Meeting of the Berkeley Linguistics Society, pp. 157-189.

Stanley Roy PETRICK (1965), A Recognition Procedure for Transformational Grammars, Ph.D. thesis, Department of Modern Languages, MIT, http://hdl. handle. net/1721.1/13013. 
Colin PHILLIPS (2003), Linear order and constituency, Linguistic Inquiry, 34(1):37-90.

Carl J. POLLARD (1996), On head non-movement, in Harry BUNT and Arthur VAN HORCK, editors, Discontinuous Constituency, number 6 in Natural Language Processing, pp. 279-305, Mouton de Gruyter, published Master's thesis from 1990.

Carl J. Pollard and Ivan A. SAG (1987), Information-Based Syntax and Semantics, number 13 in CSLI Lecture Notes, CSLI Publications.

Carl J. Pollard and Ivan A. SAg (1994), Head-Driven Phrase Structure Grammar, Studies in Contemporary Linguistics, The University of Chicago Press.

Paul M. Postal (2009), The incoherence of Chomsky's 'Biolinguistic' ontology, Biolinguistics, 3(1):104-123.

Adam PRZEPIÓRKOWSKI (1999), On case assignment and "adjuncts as complements", in Gert WeBelhuth, Jean-Pierre KoENIG, and Andreas KATHOL, editors, Lexical and Constructional Aspects of Linguistic Explanation, number 1 in Studies in Constraint-Based Lexicalism, pp. 231-245, CSLI Publications.

Geoffrey K. Pullum (1985), Assuming some version of X-bar Theory, in Papers from the 21st Annual Meeting of the Chicago Linguistic Society, pp. 323-353.

Geoffrey K. Pullum (1989), Formal linguistics meets the boojum, Natural Language and Linguistic Theory, 7(1):137-143, http://dx.doi.org/10.1007/BF@०141350.

Geoffrey K. PUllum (1991), The Great Eskimo Vocabulary Hoax and Other Irreverent Essays on the Study of Language, The University of Chicago Press.

Geoffrey K. PUlLum (2007), The evolution of model-theoretic frameworks in linguistics, in Model-Theoretic Syntax at 10 - Proceedings of the ESSLLI 2007 MTS@10 Workshop, August 13-17,pp. 1-10, http://cs. earlham.edu/esslli@7mts/.

Geoffrey K. PUllum and Barbara C. ScHOlz (2001), On the distinction between generative-enumerative and model-theoretic syntactic frameworks, in Philippe DE Groote, Glyn MORRILL, and Christian RETOR, editors, Logical Aspects of Computational Linguistics: 4th International Conference, number 2099 in Lecture Notes in Computer Science, pp. 17-43, Springer Verlag.

Geoffrey K. Pullum and Barbara C. SCHOLz (2002), Empirical assessment of stimulus poverty arguments, The Linguistic Review, 19(1-2):9-50.

Marc Richards (2015), Minimalism, in Artemis AleXIAdou and Tibor KIss, editors, Syntax - Ein internationales Handbuch zeitgenössischer Forschung, volume 42 of Handbooks of Linguistics and Communication Science, Mouton de Gruyter, 2nd edition. 
John Robert Ross (1967), Constraints on Variables in Syntax, Ph.D. thesis, MIT, http://www.eric.ed.gov/, reproduced by the Indiana University Linguistics Club.

Ivan A. SAG (1997), English relative clause constructions, Journal of Linguistics, 33(2):431-484, http://lingo . stanford . edu/sag/papers/rel-pap. pdf.

Ivan A. SAG (2010), English filler-gap constructions, Language, 86(3):486-545, http://lingo.stanford.edu/sag/papers/xcons.pdf.

Ivan A. SAG (2012), Sign-based construction grammar: An informal synopsis, in Hans C. BOAS and Ivan A. SAG, editors, Sign-based Construction Grammar, number 193 in CSLI Lecture Notes, pp. 69-202, CSLI Publications, http://lingo.stanford.edu/sag/papers/theo-syno.pdf.

Ivan A. SAG and Thomas WASOW (2011), Performance-compatible competence grammar, in Robert BORSLEY and Kersti BÖRJARS, editors,

Non-Transformational Syntax: Formal and Explicit Models of Grammar: A Guide to Current Models, pp. 359-377, Blackwell Publishing Ltd.

Ivan A. SAG, Thomas WASOW, and Emily M. BENDER (2003), Syntactic Theory: A Formal Introduction, number 152 in CSLI Lecture Notes, CSLI Publications, 2nd edition.

Pollet SAMVELian (2007), A (phrasal) affix analysis of the Persian Ezafe, Journal of Linguistics, 43:605-645.

Uli SAUERLAND and Paul Elbourne (2002), Total reconstruction, PF movement, and derivational order, Linguistic Inquiry, 33(2):283-319.

Harris B. SAVIN and Ellen PERCHONOCK (1965), Grammatical structure and the immediate recall of English sentences, Journal of Verbal Learning and Verbal Behavior, 4(5):348-353.

Barbara C. SCHOLz and Geoffrey K. PULLUM (2002), Searching for arguments to support linguistic nativism, The Linguistic Review, 19(1-2):185-223.

Edward P. STABLER (1987), Restricting logic grammars with Government-Binding Theory, Computational Linguistics, 13(1-2):1-10.

Edward P. STABLER (1992), The Logical Approach to Syntax: Foundations, Specifications, and Implementations of Theories of Government and Binding, ACL-MIT Press Series in Natural Language Processing, MIT Press.

Edward P. STABLER (2001), Minimalist grammars and recognition, in Christian ROHRER, Antje ROSSDEUTSCHER, and Hans KAMP, editors, Linguistic Form and its Computation, number 1 in Studies in Computational Linguistics, pp. 327-352, CSLI Publications.

Edward P. STABLER (2010), After Governement and Binding Theory, in Johan F. A. K. VAN Benthem and G. B. Alice TER MEulen, editors, Handbook of Logic and Language, pp. 395-414, MIT Press, 2nd edition, http://www. linguistics.ucla.edu/people/stabler/afterGB.pdf. 
Edward P. STABLER (2011), Computational perspectives on Minimalism, in Cedric BoECKX, editor, The Oxford Handbook of Linguistic Minimalism, chapter 27, pp. 616-641, Oxford University Press, http:

//www. linguistics .ucla. edu/people/stabler/Stabler10-Min. pdf.

Mark J. STEEDMAN and Jason BALDRIDGE (2006), Combinatory Categorial Grammar, in Keith BROWN, editor, Encyclopedia of Language and Linguistics, pp. 610-621, Elsevier, 2nd edition.

Luc STeEls, editor (2011), Design Patterns in Fluid Construction Grammar, number 11 in Constructional Approaches to Language, John Benjamins Publishing Co.

Luc STEELS (2013), Fluid Construction Grammar, in Thomas HofFMANN and Graeme TROUSDALE, editors, The Oxford Handbook of Construction Grammar, Oxford University Press.

Oliver SUHRE (1999), Computational Aspects of a Grammar Formalism for Languages with Freer Word Order, Master's thesis, Department of Computer Science, Eberhard-Karls-Universität Tübingen, http://www.sfs. uni-tuebingen.de/hpsg/archive/bibliography/ papers/suhre_lsl-thesis.pdf.

Michael K. TAnenhaus, Michael J. Spivey-Knowlton, Kathleen M. EBERHARD, and Julie C. SEDIVY (1995), Integration of visual and linguistic information in spoken language comprehension, Science, 268(5217):1632-1634, http://www. bcs. rochester .edu/people/mtan/ publications/1995Tanenhaus_Sci.pdf.

Michael K. TANEnhaus, Michael J. Spivey-Knowlton, Kathleen M. EBERHARD, and Julie C. SEDIVY (1996), Using eye movements to study spoken language comprehension: Evidence for visually mediated incremental interpretation, in Toshio INUI and James L. MCCLELLAND, editors, Information Integration in Perception and Communication, number XVI in Attention and Performance, pp. 457-478, MIT Press.

Michael TOMASELlo (2003), Constructing a Language: A Usage-Based Theory of Language Acquisition, Harvard University Press.

Frank VAN EYNDE and Liesbeth Augustinus (2014), Complement raising, extraction and adpostion stranding in Dutch, in Proceedings of the 21st International Conference on Head-Driven Phrase Structure Grammar, University at Buffalo, pp. 156-175, http://cslipublications.stanford.edu/HPSG/ 2014/vaneynde-augustinus . pdf.

Remi VAN TRIJP (2013), A comparison between Fluid Construction Grammar and Sign-Based Construction Grammar, Constructions and Frames, 5(1):88-116. Remi VAN TRIJP (2014), Long-distance dependencies without filler-gaps: A cognitive-functional alternative in Fluid Construction Grammar, Language and Cognition, pp. 1-29. 


\section{Stefan Müller}

Mettina Veenstra (1998), Formalizing the Minimalist Program, Ph.D. thesis, Rijksuniversiteit Groningen.

Arnim VON STECHOW (1996), The different readings of wieder "again": A structural account, Journal of Semantics, 13(2):87-138.

Moira YiP, Joan MALING, and Ray S. JACKENDOFF (1987), Case in tiers, Language, 63(2):217-250.

Arnold M. ZWICKY, Joyce FrIEDMAN, Barbara C. HALL, and Donald E. WALKER (1965), The MITRE syntactic analysis procedure for Transformational Grammars, in Proceedings of the FALL Joint Computer Conference, pp. 317-326, http://doi. ieeecomputer society.org/10.1109/AFIPS.1965.108.

This work is licensed under the Creative Commons Attribution 3.0 Unported License. http://creativecommons .org/licenses/by/3.๑/ 